\title{
Validating Performance Models for Hybrid Power Plant Control Assessment
}

\author{
Lennart Petersen ${ }^{1,2, *}$, Florin Iov ${ }^{1}$, German Claudio Tarnowski ${ }^{2}$, Vahan Gevorgian ${ }^{3}$, \\ Przemyslaw Koralewicz ${ }^{3}$ (D) and Daniel-Ioan Stroe ${ }^{1}$ (D) \\ 1 Department of Energy Technology, Aalborg University, 9220 Aalborg, Denmark; fi@et.aau.dk (F.I.); \\ dis@et.aau.dk (D.-I.S.) \\ 2 Vestas Wind Systems, 8200 Aarhus N, Denmark; getar@vestas.com \\ 3 National Renewable Energy Laboratory, Golden, CO 80401, USA; vahan.gevorgian@nrel.gov (V.G.); \\ przemyslaw.koralewicz@nrel.gov (P.K.) \\ * Correspondence: lepte@vestas.com; Tel.: +45-5221-1266
}

Received: 11 October 2019; Accepted: 9 November 2019; Published: 13 November 2019

\begin{abstract}
The need for simple, but accurate performance models of wind turbine generators (WTGs), photovoltaic (PV) plants, and battery energy storage systems (BESS) for various hybrid power plant (HPP) studies motivates the present work. Particularly, the development and verification stage of HPP controls requires reduced-order models to minimize the complexity and computation effort of simulation platforms. In this paper, such models are proposed, and the most essential parts of the models are validated through field measurements. The models target power system integration studies involving active and reactive power, as well as frequency and voltage regulation where detailed models, as proposed in the standards, can be cumbersome. Field measurements of two Vestas WTGs, one 1-MW PV plant, and one 1-MW/1-MWh BESS are used for model validation. The results show that the WTG and PV performance models correctly estimate the power generation variability according to fluctuations in wind speed and solar irradiance. The BESS performance model provides satisfactory results related to grid-forming control performance and estimation of state-of-charge. The presented validation work enables using the proposed performance models for power system studies and HPP control design in all model-based design stages, that is, preliminary analysis, design, verification, and validation with a high level of confidence.
\end{abstract}

Keywords: hybrid power plant; wind power; solar photovoltaic; battery storage; performance models; control assessment; model-based design; validation

\section{Introduction}

One trend in modern energy systems is to explore capabilities for incorporating multiple distributed energy resources (DERs) (e.g., wind power, solar photovoltaic (PV), biomass) and energy storage, forming so-called hybrid power plants (HPPs). In the case of grid-integrated HPPs, hybridization is justified by the complementarity of renewable resources (wind, solar), and hence a better use factor of the electrical infrastructure (balance of plant). Moreover, synergies in development, installation, and service, as well as enhanced grid ancillary services, lead to an increased business case certainty [1-4]. In emerging and frontier markets, significant development is predicted toward stand-alone hybrid solutions (i.e., off-grid HPPs) to ensure rural electrification and supplying remote industrial sites (e.g., mining areas) [5-7].

Developing a robust and efficient control solution for HPPs poses many challenges. Certain power management strategies (millisecond to second scale) are required to enable stable operation of HPPs, thus ensuring, for example, voltage and frequency regulation, and enabling various other functions 
such as power gradient reduction, capacity firming, and congestion management. A central hybrid power plant controller (HPPC) is commonly used because grid requirements need to be fulfilled at one particular point on the grid, that is, the point of common coupling $[1,8,9]$. On the other hand, energy management functions (minute to hour scale) need to ensure HPP use cases related to energy market participation (e.g., energy arbitrage, load following, primary/secondary/tertiary controls) and cost-optimal and reliable plant operation.

Accurate, yet simple models of wind turbine generators (WTGs), PV systems, and battery energy storage systems (BESSs) are required to verify various control algorithms in HPPs or to conduct various power system studies in general; however, the level of detail is to be reduced to the relevant dynamics for active and reactive power, as well as frequency and voltage regulation. More detailed DER models increase the computational burden of simulation platforms, particularly in large power systems with high penetration levels of various DERs (e.g., multi-MW HPPs, low-voltage feeders with high PV penetration, microgrids). On the one hand, extensive offline simulation studies are performed during the control design stage. On the other hand, real-time hardware-in-the-loop (RT-HIL) co-simulation enables testing a certain control platform (e.g., HPPC) in the final stage of a model-based design process, as described in the work of [9]. The large number of system nodes introduced by detailed DER models (e.g., by adding WTG aerodynamic and mechanical systems) will extend the simulation time and might even violate the real-time criterion during RT-HIL testing. Another reason for the need for simpler performance models is the difficulty of accessing manufacturer-specific data for all physical and control systems. Thus, generic models based on public data-sheets that capture the overall response of the assets are needed.

The standard WTG model proposed by the IEC Committee in IEC 61400-27-1 is commonly used to study dynamic power system phenomena, such as small-disturbance voltage stability, rotor angle stability, and frequency stability; however, it is not designed for studies with wind speed variability. The Type IV WTG model developed by the authors of [10] is based on the IEC 61400-27-1 model and additionally reflects wind power variations according to wind speed fluctuations. Moreover, it allows for the integration of new WTG controls, such as inertial response and power system oscillation damping. Both models, however, require detailed representation of most turbine physical characteristics and control loops, that is, pitch, aerodynamic, and mechanical models, as well as outer and inner control loops for power converters, which might not be necessary when studying the previously mentioned power and energy management functions. The proposed WTG model in this paper aims to reflect the dynamics of any Type III or Type IV WTG that can be described as a current-controlled voltage source.

Widely accepted performance models of PV arrays have been developed and are continuously updated by Sandia National Laboratories [11]. Such models provide an accurate estimate of the steady-state power output, but they do not represent the dynamic behavior on the millisecond to second base. Grid-integration studies are often performed using the response time of maximum power point tracking (MPPT) and inverter controls [12,13]; however, the solar irradiance variability, which depends on cloud conditions and PV array size, is not captured in such models. In the works of [14,15], the entire PV plant is modeled as a first-order system to capture power fluctuations based on irradiance data; however, such a model does not include any efficiency metrics and power control loops, which are required to represent the PV performance for power system studies.

The described WTG and PV models in this paper provide a simple, but accurate approach to capture active power output variations by wind speed and solar irradiance, respectively, as well as changes in active and reactive power set points.

Modeling a BESS for grid integration studies is usually realized by reducing the model complexity to inverter characteristics and controls. This is a fair approach because the response times for active and reactive power changes are dominated by the inverter, whereas the battery is limited by specified C-rate and available energy capacity only [16]. Traditionally, BESS are operated in grid-following mode (PQ control); however, because of the ability of their voltage source converters to provide 
grid-forming operation (Vf control) in bidirectional power flow modes, modern BESS can provide valuable dispatchability and resilience in both microgrid and bulk power systems. This paper aims to validate a BESS performance model with grid-forming droop control. With regard to energy management functions in power systems, it is necessary to provide a good estimate on the expected available BESS capacity (state-of-charge; SOC) applicable to, for example, intraday/day-ahead market operations or energy management system functions in microgrids. The present literature suggests various modeling methods for SOC estimation that require more or less detailed knowledge on the battery characteristics $[17,18]$. The major challenges are that, first, most required parameters are proprietary information and, second, they highly depend on the given battery technology and manufacturer. The BESS performance model proposed in this paper includes a simple Wh-counting method that can be used for various battery technologies. It only requires a set of parameters that are typically provided in product specification data sheets. The studies for model validation demonstrate that it provides satisfactory results for short-term estimation of the available capacity in lithium-ion (Li-ion) batteries.

The described performance models for WTGs, PV, and BESS in Section 2 can be used for a wide range of power system studies involving active and reactive power as well as frequency and voltage control. Some significant applications are ancillary service provisions of renewable power plants [19-22] and operational uses cases with HPPs yet to be explored such as power gradient reduction, capacity firming, and load following. Section 2 further specifies the model scope, interfaces, and application purposes. Section 3 outlines the scope and performance metrics of the presented validation work. Sections 4-6 cover the test setups and results for validating the WTG, PV, and BESS models, respectively. Field measurements of two Vestas WTGs, that is, V52-850 kW and V80-2 MW, located in Denmark, are used to demonstrate the model validity for various unit ratings. A 1-MW PV plant and 1-MW/1-MWh BESS located on the National Renewable Energy Laboratory (NREL) campus in Colorado, USA, provide test data for validating the remaining models. Section 7 presents the paper summary and outlook for further validation work.

\section{DER Performance Models}

\subsection{Model Scope, Interface, and Application}

This section describes the DER performance models that are applicable for power system stability studies involving active and reactive power, as well as frequency and voltage control. The simplification level of the models is targeted to represent the dynamic response behavior of $P, Q, V$, and $f$. Hence, detailed models of the individual power sources (i.e., WTG aerodynamic and mechanical system, PV cells, battery cells) are not included.

The models are not targeted for studies with more advanced DER controls, that is, inertial response, power oscillation damping, fault ride-through, or the assessment of subsynchronous resonances or asymmetric disturbances.

A brief guideline for the application of the proposed DER performance models is given by a generic example for the model interface shown in Figure 1. The performance models of grid-tied DERs (e.g., WTG, PV) are described as a current-controlled voltage source, regulating active and reactive power, which act as output to the grid model. The frequency bandwidth of these performance models is limited to $f_{b w}=1 \mathrm{~Hz}$ accounting for a minimum sampling time $\tau_{s}=100 \mathrm{~ms}$ of renewable resource data, that is, wind speed and solar irradiance [23]. On the other hand, a BESS in grid-forming mode is represented as a controlled Vf source, with voltage and frequency as the model outputs. Here, the model bandwidth depends on the fastest time constant of the Vf control loops being captured in the model (e.g., $f_{b w}=160 \mathrm{~Hz}$ for $\tau_{V f c t r l}=1 \mathrm{~ms}$ ). 


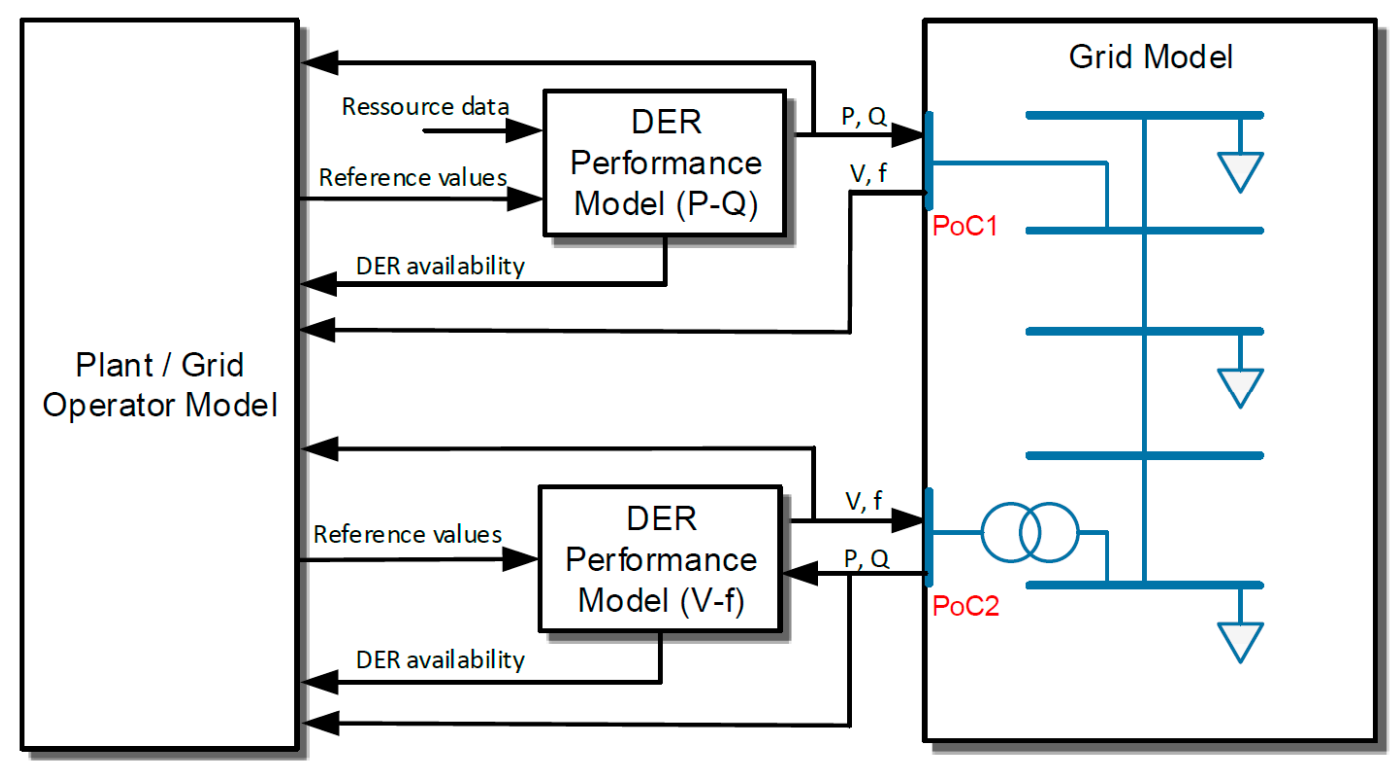

Figure 1. Interface between distributed energy resource (DER) performance models, grid model, and plant/grid operator model.

Each DER performance model outputs its status of power and/or energy availability. Reference values are provided by the plant/grid operator model, which represents, for example, the HPPC platform or the grid operator's control center. The plant/grid operator model takes all grid variables $(\mathrm{P}, \mathrm{Q}, \mathrm{V}, \mathrm{f})$ from either the DER performance model or the grid model.

The use of DER performance models is essential in all model-based design stages, that is, preliminary analysis, design, verification, and validation in the RT-HIL framework [24]. During the initial control development and tuning process (e.g., of HPPC functions), reduced-order models of the power system and DERs are required to apply classic control design tools, as well as to minimize the simulation time. Continuous time models are always required in the tuning methodology for complex systems with a wide range of time constants. Then, translation of these continuous time models in the Z-domain shall be considered in order to keep the overall model bandwidth. Here, a very detailed model of all control loops and subsystems in a DER might require a high sampling time to capture all the dynamics. Alternatively, the use of multiple sampling times for subsystems including their control will unnecessarily increase the complexity of the discretization process.

Then, verification and validation of control algorithms on bulk power systems necessitates testing the controller platform coupled with a real-time model of the power system including DERs, that is, WTGs, PV plants, BESSs. In this way, the controller platform including the initially designed algorithms can be tested and verified under realistic operating conditions that cannot be met during field-test trials. Critical power system events that cannot occur during the plant commissioning process - for example, N-1 contingencies, high overloading, high renewable generation, and large frequency excursions-can be replicated in a controlled environment. This requires the use of validated DER models. Again, reduced-order models are essential to account for the computational effort during RT-HIL co-simulations.

\subsection{Wind Turbine}

A performance model for the WTG is depicted in Figure 2 and described in the subsequent subsections [25]. The mathematical description of the rotor inertia effect block is provided by the authors in [26], whereas the remaining model add-ons are developed specifically for the power system studies in the scope as stated in Section 2.1. 


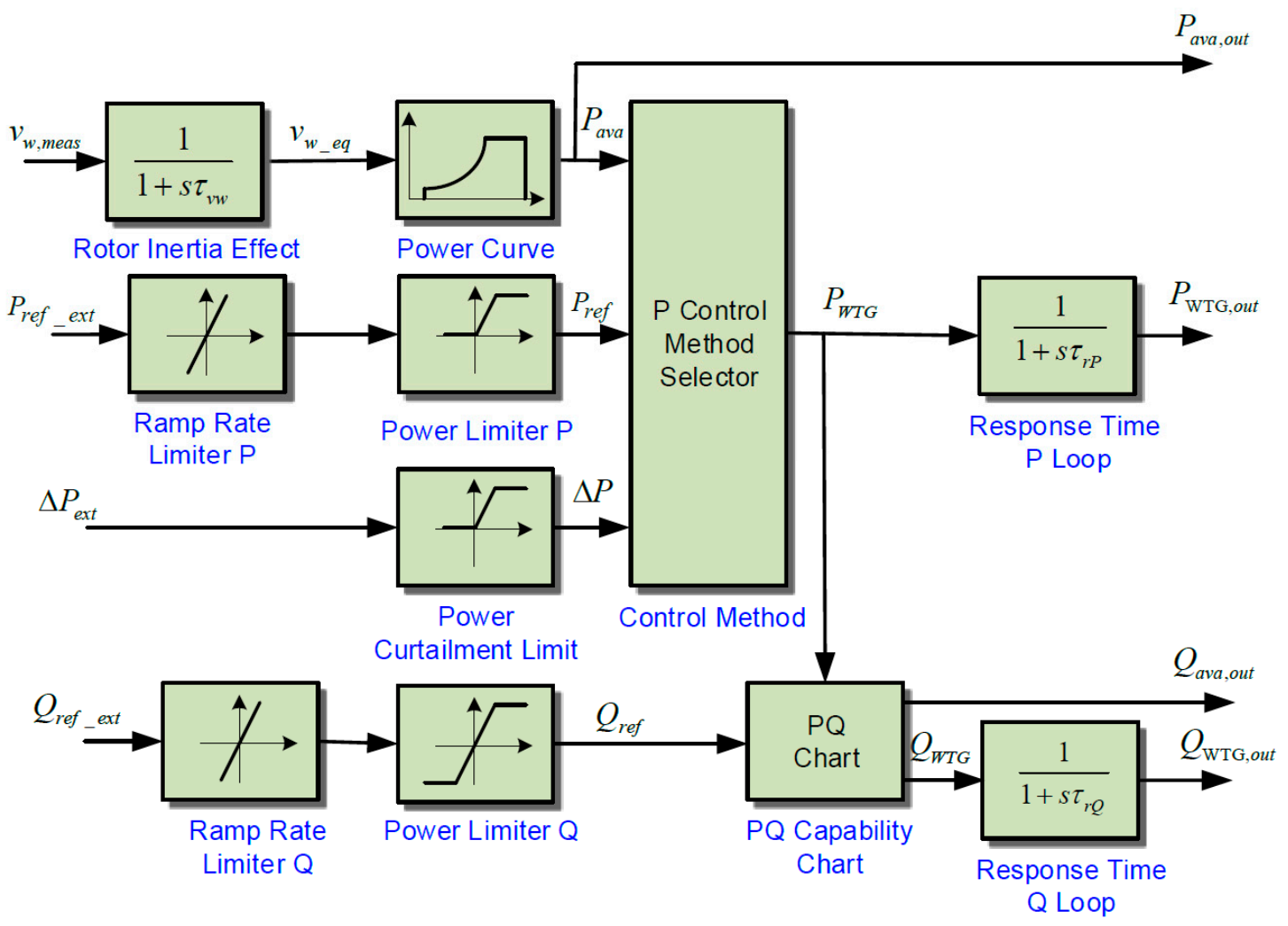

Figure 2. Block diagram of wind turbine performance model. Reprint with permission [25]; (Copyright 2016, Technical University of Denmark).

\subsubsection{Rotor Inertia Effect}

The position and time variability of wind speed on the WTG's rotor plane and the resulting mechanical torque in the generator shaft are filtered by the rotor inertia and the MPPT time constant. According to the work of [26], a first-order low-pass filter can be considered to capture this smoothening effect. This is valid because the proposed WTG model neglects a representation of the mechanical system. A natural time constant, $\tau_{v w, 0}$, which represents the time response of the WTG to attain rated speed from standstill, is proposed in the work of [26]. It is determined by the rated angular speed, $\omega_{\text {rated }}$; the total inertia, $J$; and the WTG torque, $T_{\text {rated }}$, at rated wind speed per Equation (1):

$$
\tau_{v w, 0}=\frac{\omega_{\text {rated }} \cdot J}{3 \cdot T_{\text {rated }}} .
$$

The time constant used for smoothing the wind speed (Figure 2) is then defined per Equation (2), where $v_{w, \text { rated }}$ is the rated wind speed of the WTG and $v_{w, \text { meas }}$ is the actual wind speed [26]:

$$
\tau_{v w}=\tau_{v w, 0} \cdot \frac{v_{w, \text { rated }}}{v_{w, \text { meas }}} .
$$

\subsubsection{Power Curve}

The active power output of the WTG, $P_{W T G}$, at the point of connection (PoC) depends on the equivalent wind speed, $v_{w, e q}$, resulting from the smoothing effect shown in Figure 2 and described by Equations (1) and (2). It is generally given by a turbine-specific power curve that is given as a one-dimensional lookup table expressing wind speed and produced power. All WTG controllers for torque, speed and pitch, which yield in MPPT, are represented in this power curve, thus containing all optimized static operating points. 


\subsubsection{Control Method}

This block selects the active power control method for the WTG. Three options are available:

- Method 1: WTG injects all the available power, $P_{a v a}$, into the grid.

- Method 2: WTG follows an active power set point, $P_{\text {ref,ext }}$, from an upper hierarchical control level. The power reference is restricted by ramp rates imposed by power converter limitations and a maximum power limit, that is, 1 p.u.

- Method 3: WTG injects curtailed active power into the grid ("Delta" control) and is able to add an additional contribution according to the reference specified by $\Delta P_{\text {ext }}$. This signal shall not be higher than the maximum allowed curtailment, $\Delta P_{\text {lim }}$. Such functionality might be required by system operators to facilitate some "spinning reserve" by WTGs.

\subsubsection{PQ Chart}

A manufacturer-specific PQ chart characteristic (P over Q) for the WTG system is implemented in the model. An example is illustrated in Figure 3a, where reactive power of \pm 0.33 p.u. is available at every active power operating point.

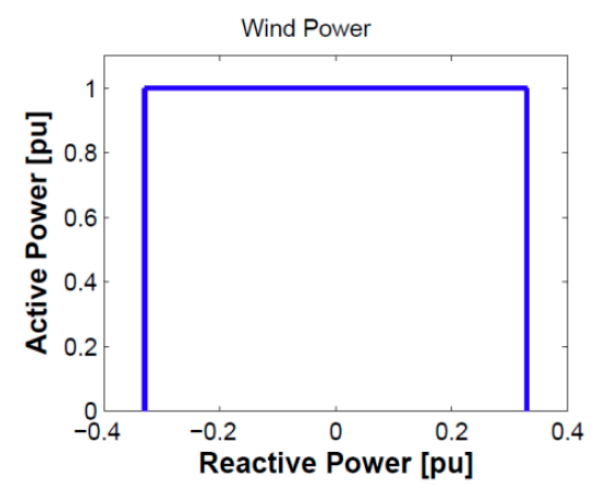

(a)

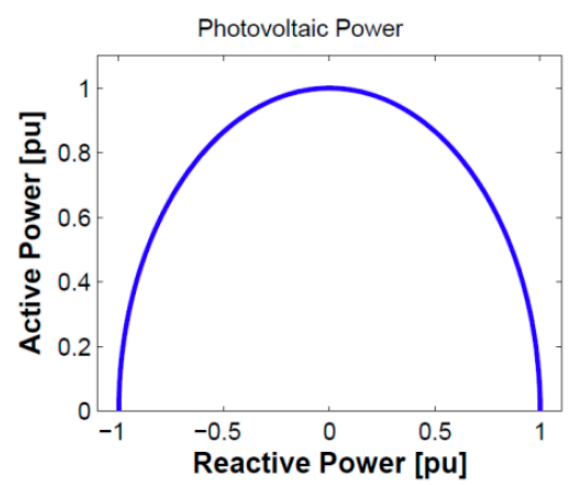

(b)

Figure 3. (a) PQ chart for wind turbines; (b) PQ chart for photovoltaic (PV) systems.

\subsubsection{Response Time for Power Control Loops}

The response time for WTG active and reactive power injected in the PoC takes into account the internal active and reactive power control loops. Typical time response values of the closed-loop system are $\tau_{r P}=1 \mathrm{~s}$ [27] and $\tau_{r Q}=0.2 \mathrm{~s}$ [28].

\subsection{Solar Photovoltaic System}

A performance model for the PV is depicted in Figure 4 and elaborated in the subsequent subsections [25]. The mathematical description of the PV low-pass filter block is provided by the authors in $[14,15]$, whereas the remaining model add-ons are developed specifically for the power system studies in the scope as stated in Section 2.1. 


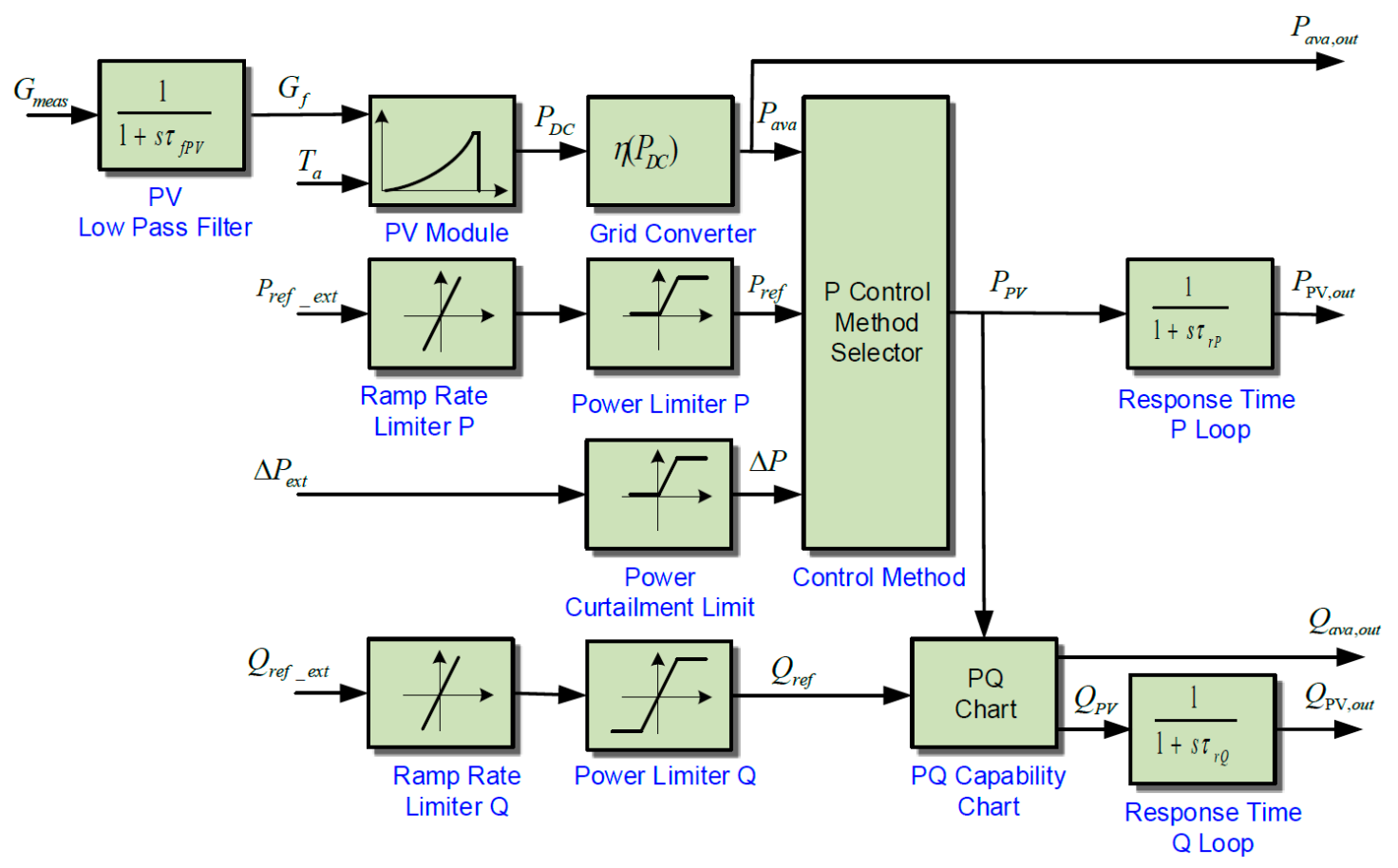

Figure 4. Block diagram of the photovoltaic system performance model. Reprint with permission [25]; (Copyright 2016, Technical University of Denmark).

\subsubsection{PV Irradiance}

A low-pass filter is applied in order to associate solar irradiance, measured at one single point, with the power output of the entire PV plant. The filter cutoff frequency is determined according to the work of [14]. An expression for realistic estimation of the cutoff frequency, $f_{c, P V}$, is proposed by the authors in [15]. It is based on different measurement campaigns, that is, two months of $10 \mathrm{~s}$ data and two years of 10 min data from PV systems of different sizes.

The cutoff frequency is calculated per Equation (3), where $x$ and $y$ are coefficients ascertained by curve-fitting techniques using the measured data, and $S$ is the area of the PV system [15]:

$$
f_{c, P V}=x \cdot S^{y}
$$

Applying the procedures and results published in the works of $[14,15]$, the cutoff frequency as a function of installed PV plant capacity, $P_{P V}$, rated, is formulated in Equation (4), with $a=0.26$ and $b=-0.499$ :

$$
f_{c, P V}=a \cdot P_{P V, \text { rated }}^{b}
$$

Thus, the resulting time constant, $\tau_{f, P V}$, is determined by Equation (5):

$$
\tau_{f, P V}=\frac{1}{2 \pi \cdot f_{c, P V}}
$$

The time constant accounts for the smoothing effect as a result of the spread of PV array in the area. The authors in [15] proposed a transfer function with $\tau_{f, P V}$ to describe the PV power output based on solar irradiance only; however, a full performance model requires additional features, that is, efficiency metrics and power control loops, to represent the dynamic behavior of PV active and reactive power output. 


\subsubsection{PV Module}

The active power output, $P_{D C}$, of the PV module is related to the plane-of-array irradiance, $G_{m e a s,}$ and temperature on site. The characteristics can be described by the power temperature coefficient model [11]. It is expressed by Equation (6), where $T_{c}$ is the solar cell temperature; $\gamma$ is the temperature coefficient; and $G_{S T C}, T_{S T C}$, and $P_{\text {rat }}$ are the solar irradiance, temperature, and nominal peak power, respectively, of the PV array under standard test conditions $\left(1000 \frac{\mathrm{W}}{\mathrm{m}^{2}}, 25^{\circ} \mathrm{C}\right)$.

$$
P_{D C}=\frac{G_{m e a s}}{G_{S T C}} P_{r a t}\left[1+\gamma\left(T_{c}-T_{S T C}\right)\right]
$$

\subsubsection{Grid Converter and Controls}

PV modules are connected to one or multiple grid converters, which introduces some power losses. DC power is multiplied with the converter efficiency $\eta$. A constant efficiency value can be applied or an efficiency curve $\eta\left(P_{D C}\right)$ can be implemented if sufficient data are available.

The model blocks for power control method selector are equal, as in the WTG system (see Section 2.2.3).

A representative PQ chart for PV systems is shown in Figure 3b. The response times for both active and reactive power control are represented by first-order time constants. Note that for large PV plants, $\tau_{r P} \ll \tau_{f P V}$, so that the response time of the active power control loop will not have any significant effect. For small kW systems, however, the control time response could be in the same range as the PV irradiance low-pass filter.

\subsection{Battery Energy Storage System}

A performance model for the BESS is shown in Figure 5 and described in the following subsections. The BESS converter can be operated either as a controlled PQ source (grid-following type) or as a controlled Vf source (grid-forming type) because it is fully dispatchable within the constraints of available energy capacity (SOC). The converter controls blocks describe the corresponding control loops, which can be found in the literature (e.g., the work of [29]). By adding the battery modules and converter block, a comprehensive performance model is described that is developed specifically for the power system studies in the scope (Section 2.1).

\subsubsection{Battery Modules and Grid Converter}

The battery modules and converter block in Figure 5 describes the available energy (SOC), and hence power capacity, $P_{a v a, o u t} ;$ the total energy throughput, $E_{t h}$; and total energy loss in the storage system, $E_{\text {loss }}$, based on requested AC power, $P_{\text {in }}$; the initial SOC, $S O C_{\text {ini }}$; as well as state-of-health (SOH). In this way, the efficiency losses in both the battery cells and converter are represented. The model is based on the Coulomb counting method, which accounts for the internal battery effects by means of charging and discharging efficiency.

The modeling approach for the battery modules is applicable in the following cases:

- Response time and voltage/current dynamics of the battery cells are not important. In fact, for grid applications, the relevant dynamics (i.e., AC voltages and currents) of the entire BESS are generated by the inverter system (see Section 2.4.2).

- Information is required on the actual SOC value using real-time power measurements, unless it is given by the battery management system (BMS).

- Information is required on the future SOC value based on the expected power profile, $P_{i n}$, of the BESS during a certain time period, $d t$.

- Influences of temperature, $\mathrm{C}$ rate, and self-discharge on battery performance are not relevant. The Coulomb counting method cannot remain accurate over long time periods with significant variations of these parameters. 
The described model does not provide information on the actual battery $\mathrm{SOH}$; however, it allows for the performance of lifetime assessment studies using model output variables, that is, SOC and $E_{t h}$, for post-processing techniques, such as throughput-counting or cycle-counting [30].

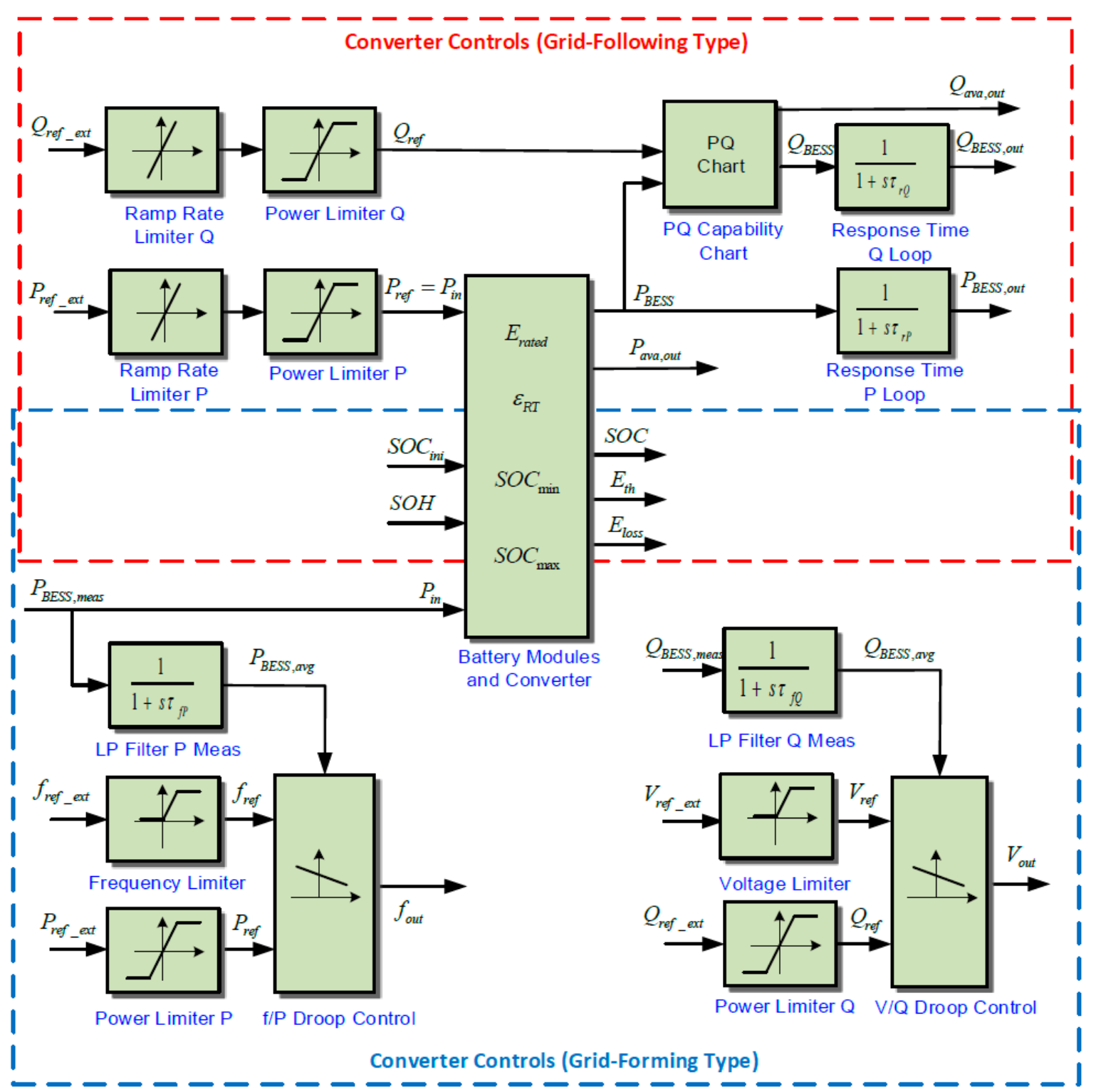

Figure 5. Block diagram of battery energy storage system performance model.

The maximum available power, $P_{a v a}$, of the battery bank is limited by the maximum charging/discharging rate, which is expressed by the so-called $C$-rate, in relation to its total storage capacity (Equation (7)).

$$
P_{c-\text { rate }, \max }=\frac{C-\text { rate }_{\max }}{1 \mathrm{~h}} \cdot E_{\max }
$$

Moreover, the available output power is restricted by the minimum and maximum SOC limits, as expressed by Equations (8) and (9) for the charging and discharging process, respectively:

$$
P_{a v a, c h}=\frac{\left(S O C_{i n i}-S O C_{\max }\right) \cdot E_{\max }}{d t \cdot \varepsilon_{c h}}
$$




$$
P_{a v a, d c h}=\frac{\left(S O C_{i n i}-S O C_{\min }\right) \cdot E_{\max } \cdot \varepsilon_{d c h}}{d t}
$$

Charging power is defined as negative, whereas discharging power is positive. $\varepsilon_{c h}$ and $\varepsilon_{d c h}$ are the efficiencies during charging and discharging. The maximum energy capacity, $E_{\max }$, is dependent on the $\mathrm{SOH}$ of the battery as a result of the degradation processes over time (Equation (10)), where $E_{\text {rated }}$ is the energy capacity at $100 \% \mathrm{SOH}$ :

$$
S O H=\frac{E_{\max }}{E_{\text {rated }}} \cdot 100 \%
$$

An overall round-trip efficiency, $\varepsilon_{R T}$, is often provided in data sheets. It assumes equal charging and discharging efficiency per Equation

$$
\varepsilon_{R T}=\varepsilon_{c h}^{2}=\varepsilon_{d c h}^{2}
$$

The requested BESS power output is limited by the available power capacity, as described by Equations (12) and (13):

$$
\begin{aligned}
& P_{B E S S, \text { ch }}=\max \left[\begin{array}{lll}
P_{\text {in }} & -P_{c-\text { rate }, \text { max }} & P_{a v a, c h}
\end{array}\right], \\
& P_{B E S S, d c h}=\min \left[\begin{array}{lll}
P_{\text {in }} & P_{c-\text { rate }, \text { max }} & P_{\text {ava }, d c h}
\end{array}\right] .
\end{aligned}
$$

Then, the expressions for internal battery charging and discharging power (Equations (14) and (15)) enable the calculation of the actual SOC [31]. It is determined by Wh-counting, as described in Equation (16) [31]:

$$
\begin{gathered}
P_{c h}=\varepsilon_{c h} \cdot P_{B E S S, c h} \approx \sqrt{\varepsilon_{R T}} \cdot P_{B E S S, c h}, \\
P_{d c h}=\frac{P_{B E S S, d c h}}{\varepsilon_{d c h}} \approx \frac{P_{B E S S, d c h}}{\sqrt{\varepsilon_{R T}}}, \\
S O C=S O C_{i n i} \pm \frac{\int P_{c h / d c h} \cdot d t}{E_{\max }} .
\end{gathered}
$$

In fact, Equation (16) is a simplification of Equation (17), which expresses the actual Coulomb counting principle (Ah-counting) [32]:

$$
S O C=S O C_{i n i} \pm \frac{\int I_{c h / d c h} \cdot d t}{Q_{\max }} .
$$

The total energy throughput, $E_{t h}$, and total energy lost in the storage system, $E_{\text {loss }}$, are calculated per Equations (18)-(20):

$$
\begin{gathered}
E_{t h}=\int\left[P_{B E S S}\right] \cdot d t, \\
E_{l o s s, c h}=\int\left[P_{B E S S}\right] \cdot d t \cdot\left(1-\varepsilon_{c h}\right) \approx \int\left[P_{B E S S}\right] \cdot d t \cdot\left(1-\sqrt{\varepsilon_{R T}}\right), \\
E_{l o s s, d c h}=\int\left[P_{B E S S}\right] \cdot d t \cdot\left(1-\varepsilon_{d c h}\right) \approx \int\left[P_{B E S S}\right] \cdot d t \cdot\left(1-\sqrt{\varepsilon_{R T}}\right) .
\end{gathered}
$$

\subsubsection{Converter Controls-Grid-Following Type}

Typically, grid-tied BESS operate in PQ-control mode, where active and reactive power are controlled independently [16]. The power references are restricted by ramp rates imposed by power converter limitations and a maximum power limit, that is, 1 p.u. (Figure 5). Moreover, the active power output, $P_{B E S S}$, is restricted by the available energy capacity, as explained in the previous subsection. Reactive power output, $Q_{B E S S}$, is limited by the corresponding $P Q$ chart. The response times for both active and reactive power control are represented by first-order time constants. 


\subsubsection{Converter Controls-Grid-Forming Type}

In grid-forming mode, the BESS forms the voltage magnitude and frequency. Such Vf control is required in microgrids by at least one DER; however, grid-forming control by converter-based DERs is also becoming more relevant in future bulk power systems with fewer synchronous generation resources. To operate in Vf-control mode, it is indispensable for the BESS to have sufficient available energy capacity to be fully dispatchable [16]. Hence, limitations in active and reactive power output by available energy capacity and PQ chart are not included in the model (Figure 5). The actual power output, $P_{B E S S, \text { meas }}$, however, is used to calculate the actual SOC, which can be regulated within the minimum and maximum limits, for example, by the microgrid energy management system.

A typical droop control scheme ( $V / Q$ and $f / P)$ is used, as expressed in Equations (21) and (22) [16]:

$$
\begin{gathered}
f=f_{r e f}-m_{f} \cdot\left(P_{B E S S, a v g}-P_{r e f}\right), \\
V=V_{r e f}-m_{f v} \cdot\left(Q_{B E S S, a v g}-Q_{r e f}\right),
\end{gathered}
$$

where $m_{f}$ and $m_{v}$ are the droop gains for frequency and voltage control, respectively. A first-order low-pass filter is typically applied for the measurement of active and reactive power $\left(P_{B E S S, a v g}, Q_{B E S S, a v g}\right)$. This means that the converter will have a delayed response of voltage and frequency to any external events indicated by changes in $P$ and $Q$ according to the selected time constants $\tau_{f P}$ and $\tau_{f Q}$.

\section{Scope and Performance Metrics of Model Validation}

This paper attempts to validate a wide range of the model capabilities presented in Section 2.

\subsection{Wind Turbine and Photovoltaic System}

One of the most crucial aspects is the correct estimation of power generation variability according to fluctuations in wind speed and solar irradiance because it determines, for example, the BESS control requirements in HPPs for power gradient reduction, frequency control, or capacity firming. Hence, the performance models for the WTG and PV systems shall be capable of satisfactorily representing the active power variations over time. One common way of analyzing power fluctuations is by assessing the rate of change of power, per Equation (23) [33]. The time interval is selected as $\Delta t=1 \mathrm{~s}$, to capture any variations in wind speed and solar irradiance [25,34].

$$
\frac{\Delta P}{\Delta t}=|P(t)-P(t-\Delta t)|
$$

\subsection{Battery Energy Storage System}

Grid-forming control of DERs is essential in microgrids, but it is becoming more relevant in large-scale power systems with low inertia, too. The droop control method is most commonly applied to facilitate parallel operation of multiple DERs. The BESS performance model in Vf control mode shall be capable of simulating the active power/frequency droop and reactive power/voltage droop with magnitude deviation of $<5 \%$.

Accurate SOC estimation in BESS is relevant for a wide range of grid applications. The BMS will generally update the real-time SOC value during operation; however, many times the BESS operator requires information on the future SOC value based on the expected charge/discharge power profile, for example, for intraday/day-ahead market operations or energy management system functions in microgrids. The BESS model shall be capable of estimating the SOC during a full cycle with a maximum deviation of $\triangle S O C=S O C_{\text {sim }}-S O C_{B M S}= \pm 5 \%$. Such deviation is acceptable, as some safety margins for the usable SOC range (e.g., between $10 \%$ and $90 \%$ ) are usually considered for various grid applications. 


\section{Wind Turbine Model Validation}

\subsection{Vestas V52-Field Measurements}

One WTG is used in this study; that is, the Vestas V52 research turbine (Type 3) located at the Technical University of Denmark (DTU) Risø campus. The test data of the WTG are listed in Table 1. A met tower is located approximately $120 \mathrm{~m}$ from the WTG, as shown in Figure 6.

Table 1. Test data of wind turbines under investigation.

\begin{tabular}{ccc}
\hline WTG Model & Vestas V52 & Vestas V80-2MW \\
\hline Location & Risø/Denmark & Bornholm/Denmark \\
Type & III & III \\
Rated power $[\mathrm{kW}]$ & 850 & 2000 \\
Rated wind speed $[\mathrm{m} / \mathrm{s}]$ & 14 & 16 \\
Rated rotor speed $[\mathrm{rpm}]$ & 26 & 16.7 \\
Rotor diameter $[\mathrm{m}]$ & 52 & 80 \\
Rotor weight $[\mathrm{t}]$ & 10 & 37.2 \\
Calculated rotor inertia constant $\tau_{0}[\mathrm{~s}]$ & 3.3 & 5.1 \\
\hline
\end{tabular}

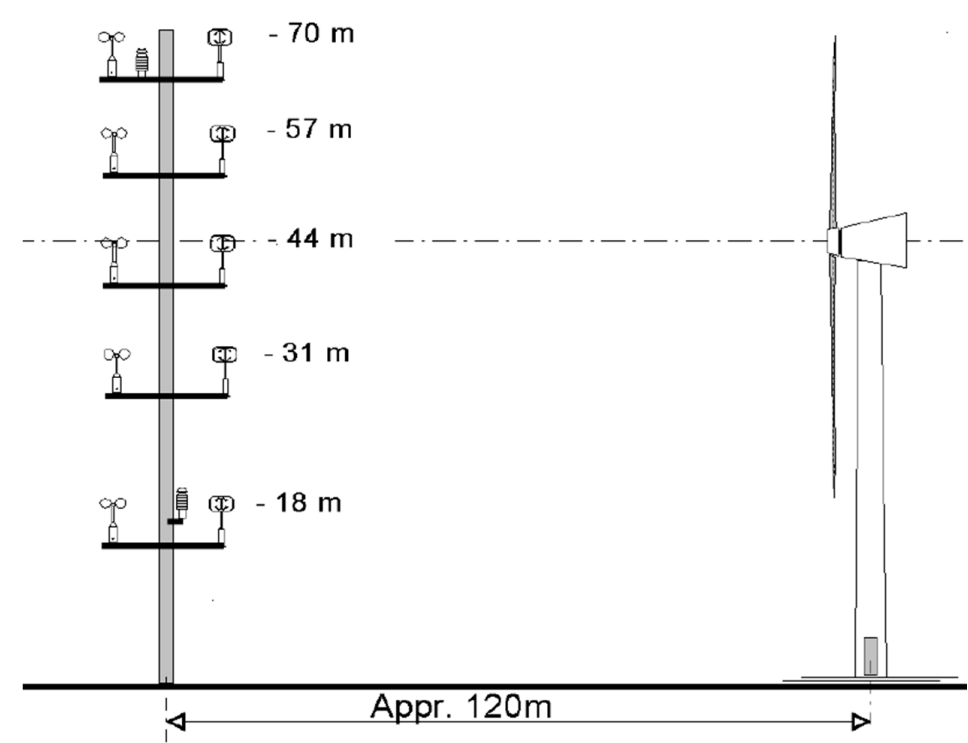

Figure 6. Field measurement setup for V52 at DTU campus [Courtesy of Technical University of Denmark].

Measurements of wind speed and direction are available at $18 \mathrm{~m}, 44 \mathrm{~m}$, and $70 \mathrm{~m}$. Moreover, several WTG measurements are provided, such as grid voltage and frequency, active and reactive power, pitch angle, and yaw position. All measurements are sampled at $35 \mathrm{~Hz}$. To cover a wide range of WTG power curves, a representative day $(\mathrm{T}=24 \mathrm{~h})$ in March 2017 with volatile wind conditions is chosen for model validation. The data distribution is illustrated in Figure 7a. During this day, the wind direction was nearly constant, with the rotor plane in front of the met tower, as illustrated in Figure 6.

\subsection{Vestas V80-2 MW-Field Measurements}

The second WTG is a Vestas V80-2 MW (Type 3) located on the Danish island of Bornholm (see Table 1). Field data at $10 \mathrm{~Hz}$ resolution are obtained from September 2009 [35]. The wind speed measured by the nacelle anemometer behind the rotor is provided together with several other measurements, such as grid voltage and frequency, active and reactive power, pitch angle, and yaw position. The measurement time period is $\mathrm{T}=5.5 \mathrm{~h}$, and a wide range of WTGs power curves is captured, as illustrated in Figure $7 \mathrm{~b}$. 


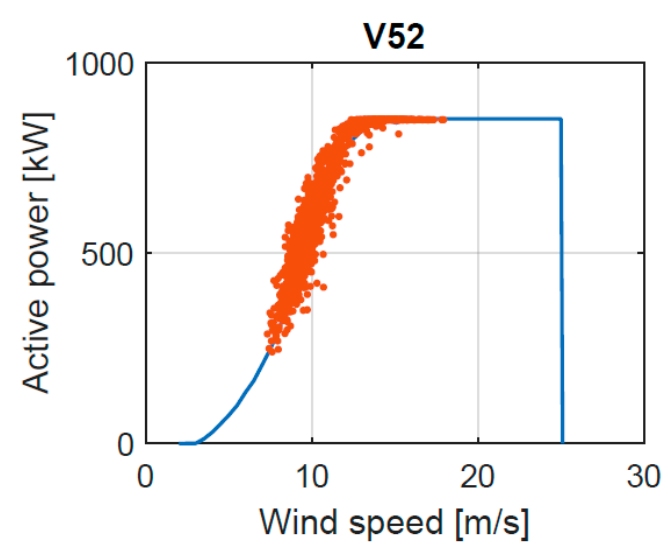

(a)

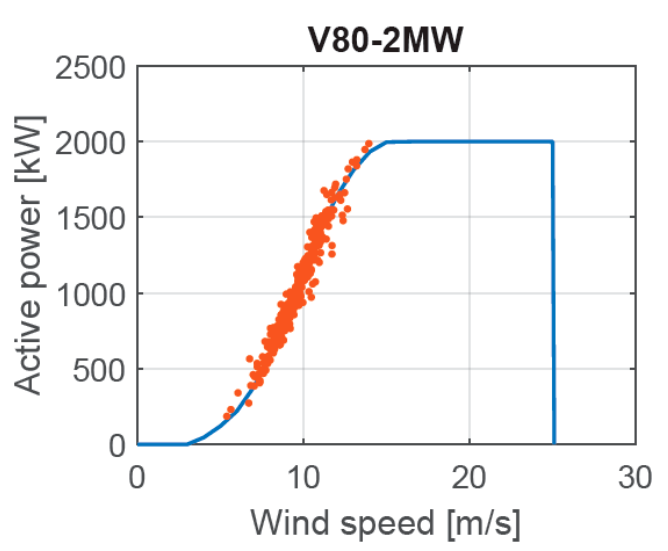

(b)

Figure 7. One minute average active power vs. wind speed during measurement campaigns for (a) V52 wind turbine generator (WTG); (b) V80-2 MW WTG.

\subsection{Validation Results}

The performance model described in Section 2 is used to simulate the WTG's active power output using the measured wind speed time series. Control method 1 is applied, that is, the WTG injects all the available power into the grid. Note that for V80-2 MW, the nacelle wind speed measured approximately $10 \mathrm{~m}$ behind the rotor is fed into the model, whereas the met mast wind speed measured at a hub height of $120 \mathrm{~m}$ in front of the rotor is used for V52. It is acknowledged that the performance of large WTGs is biased by the vertical wind shear across the rotor. Hence, for power curve measurements, a rotor equivalent wind speed is ascertained by averaging the weighted wind speed over the swept rotor area [36]. In this study, however, it is observed that averaging all wind speeds at $18 \mathrm{~m}, 44 \mathrm{~m}$, and $70 \mathrm{~m}$ results in too smoothened wind profiles, which cannot be correlated with the power output variations. Hence, only the wind speed data obtained at hub height $(44 \mathrm{~m})$ are considered for the V52 turbine.

The resulting wind speed (upper plot) and active power profile (lower plot) for a time window of 5 min are shown in Figure 8 (V52 a, V80-2 MW b).

When comparing measurements against simulations, one can note that the active power profiles of both WTGs are estimated with good precision. However, they are slightly shifted along the $x$-axis. In the case of V52, a lagging time offset in the range from $\Delta t=t_{\text {sim }}-t_{\text {meas }}==10$ to $-2 \mathrm{~s}$ is observed, which can be explained by the distance between the WTG and met mast. On the other hand, for V80, there is a leading time offset ranging from $\Delta t=2$ to $10 \mathrm{~s}$ because of the distance between the nacelle anemometer and rotor plane. It should be noted that these differences between simulations and measurements are mainly caused by the quality of input data, that is, the location of wind speed meter. However, in order to evidence the model suitability for active power and frequency control studies, it is much more relevant to assess the power generation variability, as stated in Section 3.

To validate the model performance during a longer time window $(\mathrm{T}=24 \mathrm{~h}$ for $\mathrm{V} 52, \mathrm{~T}=5.5 \mathrm{~h}$ for V80-2 MW), the cumulative distribution of the rate of change of power is assessed (Equation (23) in Section 3). Figure 9 depicts the highest percentiles (95-100\%) of $\frac{\Delta P_{W T G}}{\Delta t}$ in pu/s, comparing measurements and simulations. 
V52

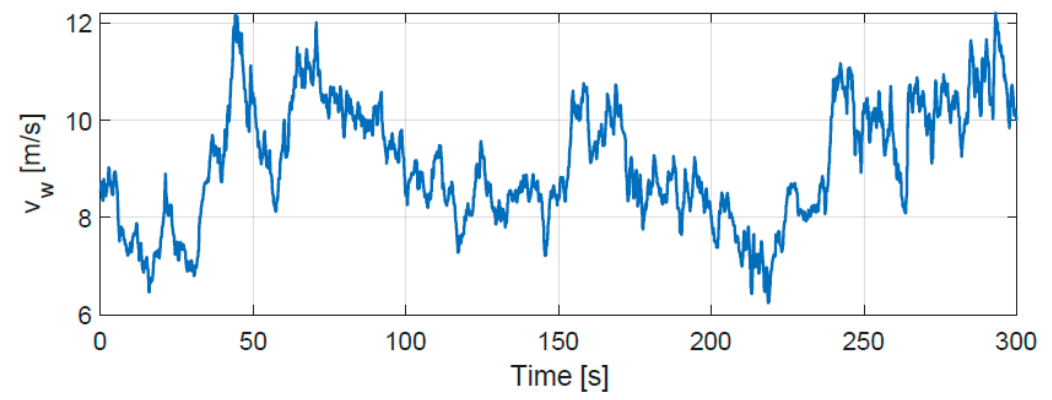

(a)

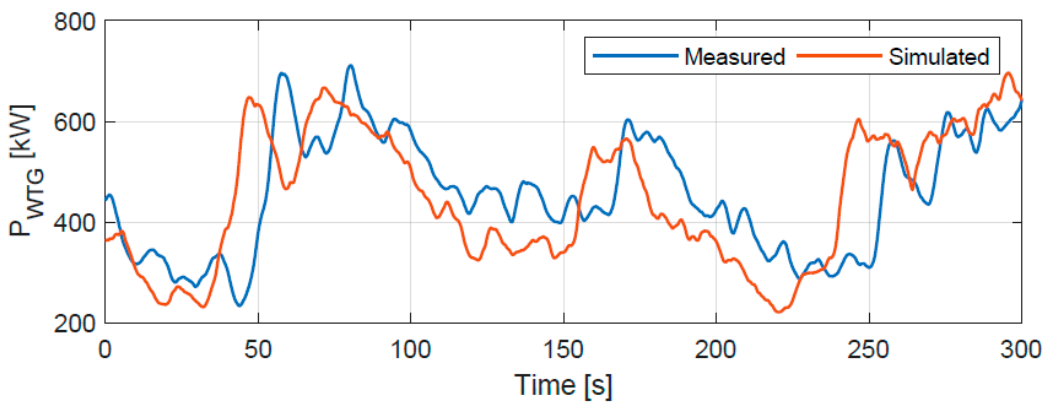

(b)

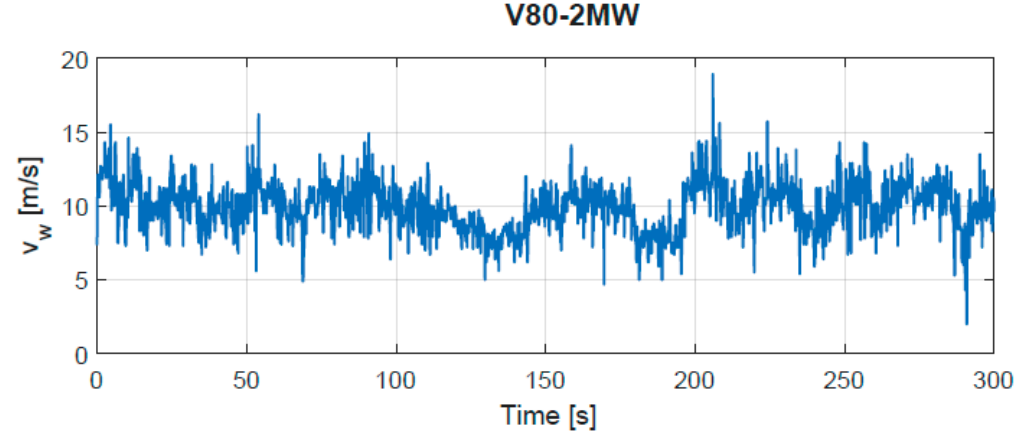

(c)

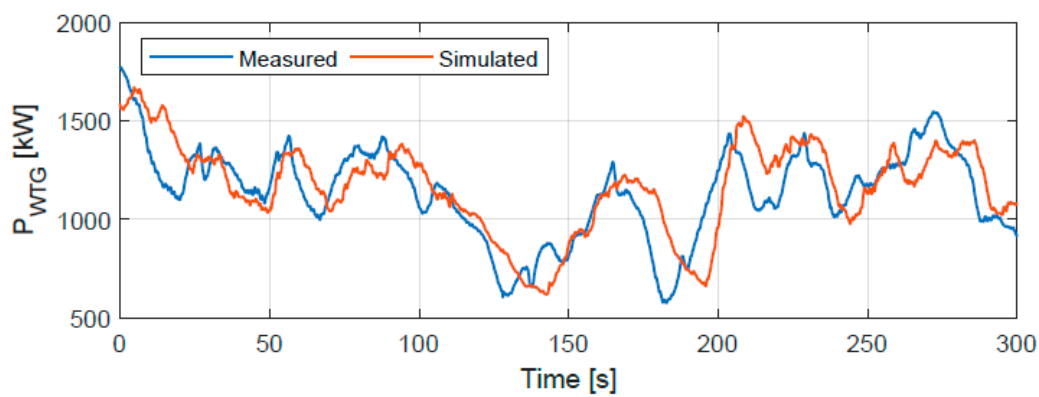

(d)

Figure 8. (a) Wind speed profile V52; (b) power output profile V52; (c) wind speed profile V80-2MW; (d) power output profile V80-2MW. 


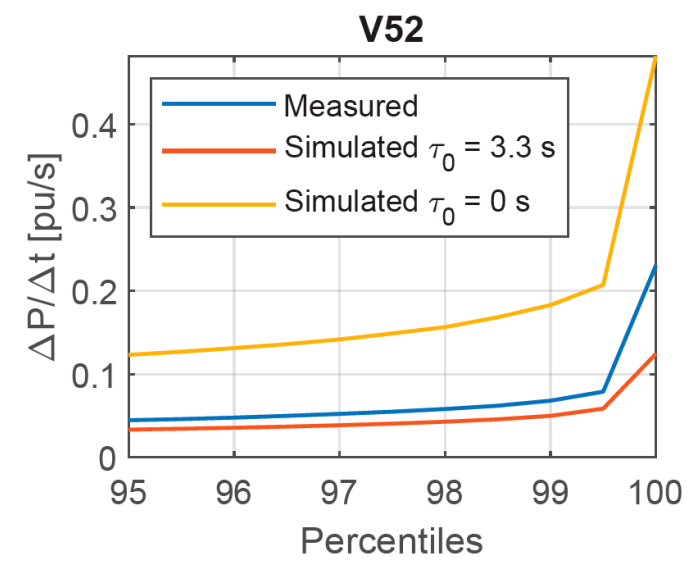

(a)

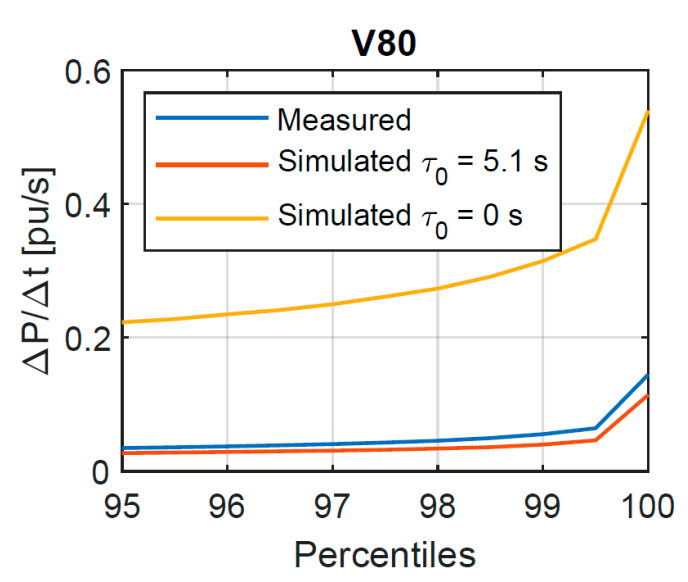

(b)

Figure 9. Percentiles of rate of change of power: (a) V52 WTG; (b) V80 WTG.

A simulation case with $\tau_{0}=0 \mathrm{~s}$ is added to demonstrate the necessity of calculating a WTG specific time constant that represents the rotor inertia effect (see Section 2). One can observe that unrealistic high ramp rates are obtained without considering the smoothing effect by the WTG rotor (yellow curve). On the other hand, there is a good match between the performance model and measurements by comparing the red versus blue curve. The ramp rates are slightly underestimated for both WTGs. This can be explained by not knowing the exact rotor equivalent wind speed because additional wind turbulences between anemometer and rotor plane are likely to occur. Overall, it is concluded that the performance model provides a satisfactory estimate of the expected power variations of the WTG with a maximum deviation of $3 \%$ up to $99.5 \%$.

\section{Solar Photovoltaic Model Validation}

\subsection{NREL Photovoltaic Plant_-Field Measurements}

Field measurement data of NREL's 1-MW PV plant located at the Flatirons Campus in Boulder, Colorado, are used to validate the PV system model. The DC power generated by Evergreen Solar $\mathrm{PV}$ modules is converted by $3 \times 333 \mathrm{~kW}$ Solaron inverters. The plant is grid-connected at a $13.2 \mathrm{kV}$ medium-voltage level. The test data of the PV plant are summarized in Table 2. Figure 10 shows the location of the PV plant. A meteo station (Site 1.9, red underline) is located $200 \mathrm{~m}$ southwest of the PV array center and measures the global horizontal irradiance (GHI) every three seconds. Clouds are usually formed in the adjacent Rocky Mountains (Figure 10b), resulting in a prevailing west-east direction of cloud movement. Electrical measurements at MV level (grid voltage and frequency, active and reactive power) are available every one second.

Table 2. Test data for photovoltaic (PV) plant under investigation.

\begin{tabular}{cc}
\hline Location & Boulder/USA \\
\hline Type & Poly-crystalline \\
Rated power $[\mathrm{kW}]$ & 1000 \\
Inverter CEC efficiency $\eta[\%]$ & 97.5 \\
Temperature coefficient $\gamma\left[\% /{ }^{\circ} \mathrm{C}\right]$ & -0.49 \\
Calculated time constant $\tau_{f P V}[\mathrm{~s}]$ & 19.2 \\
\hline
\end{tabular}

A representative day in June 2018 with significant cloud movement is selected. The daily profile is shown in Figure 11. 


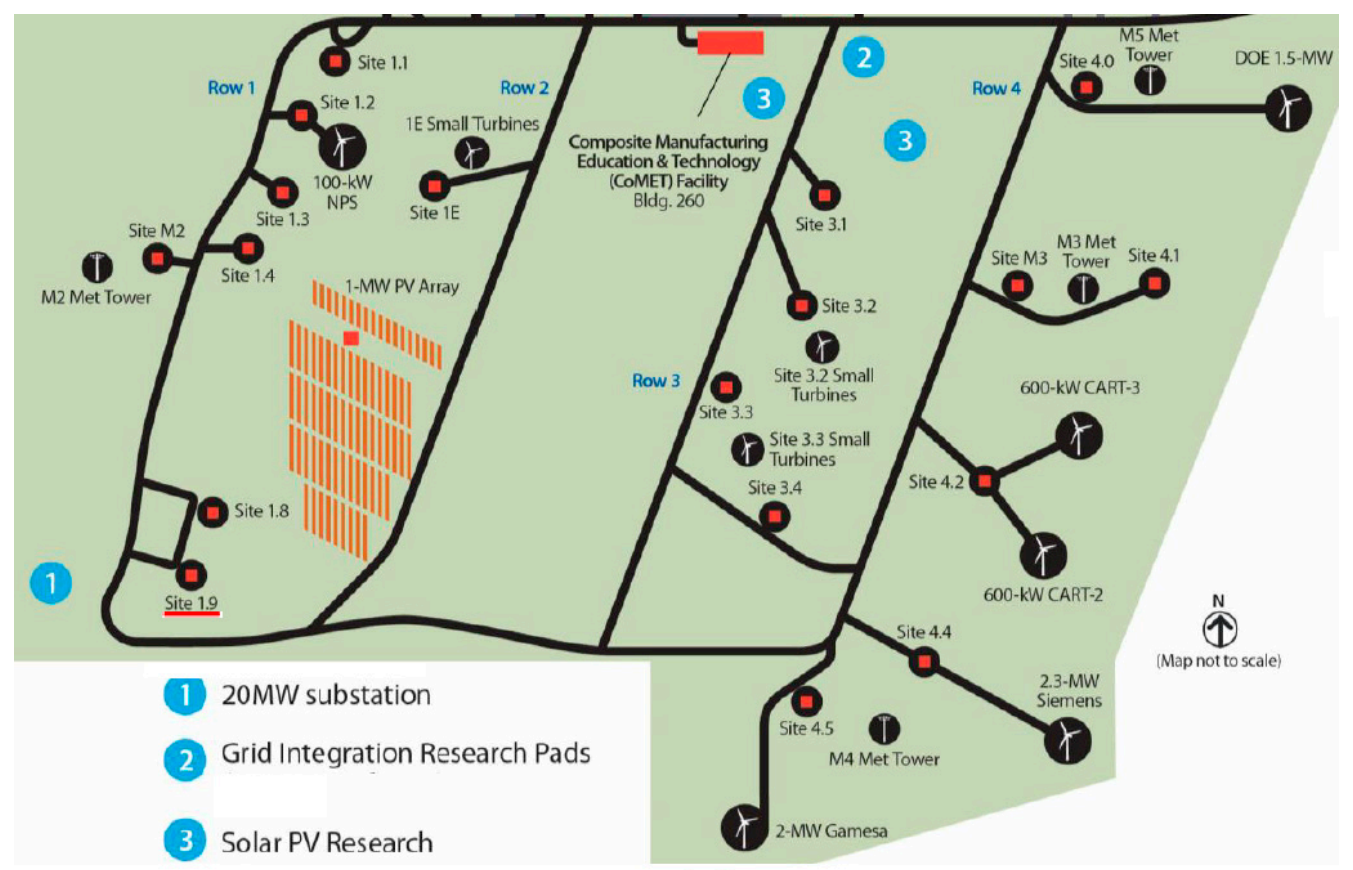

(a)

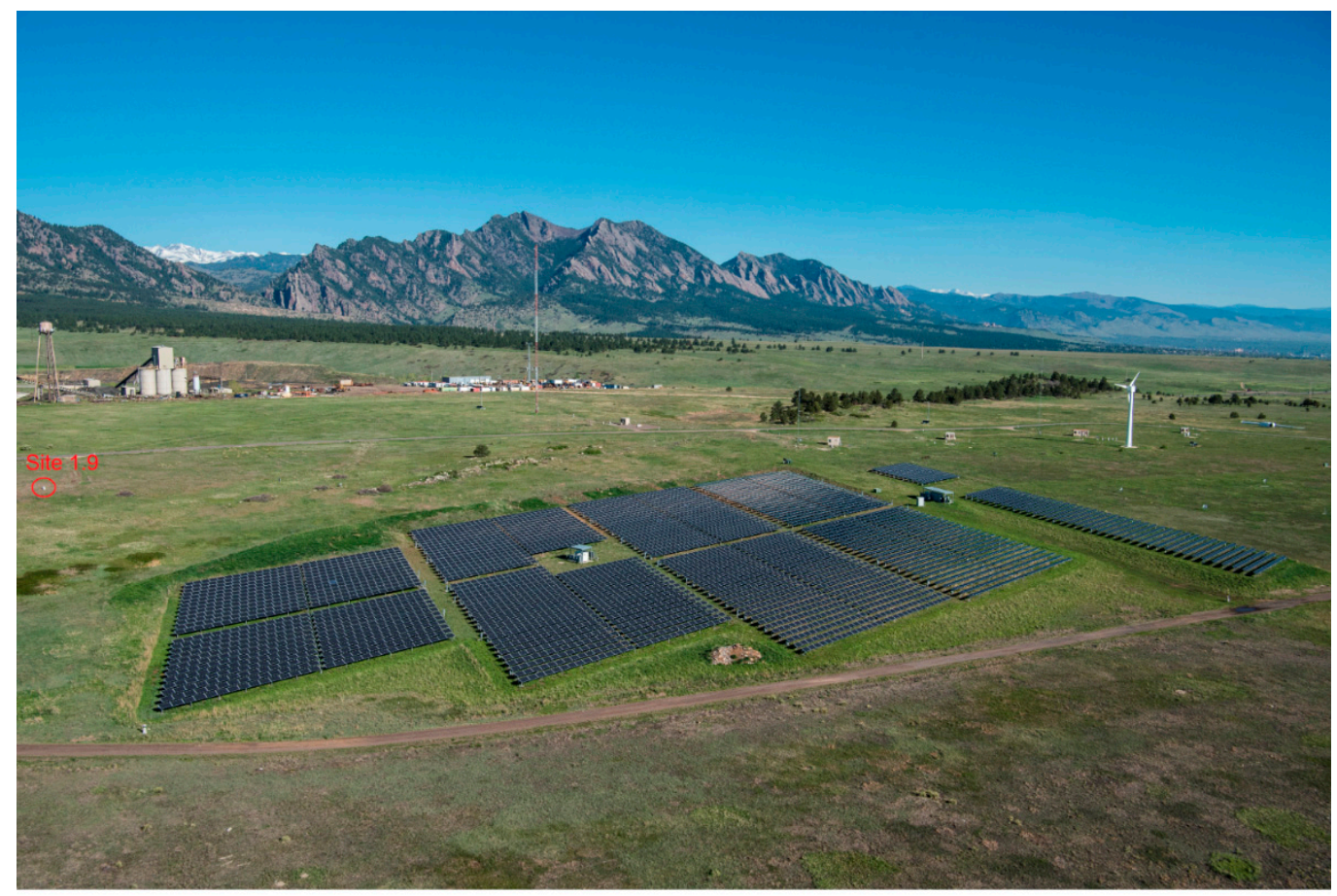

(b)

Figure 10. (a) NREL Flatirons Campus overview with global horizontal irradiance (GHI) measurements at Site 1.9 and 1-MW PV array; (b) aerial photo of the NREL Flatirons campus. 


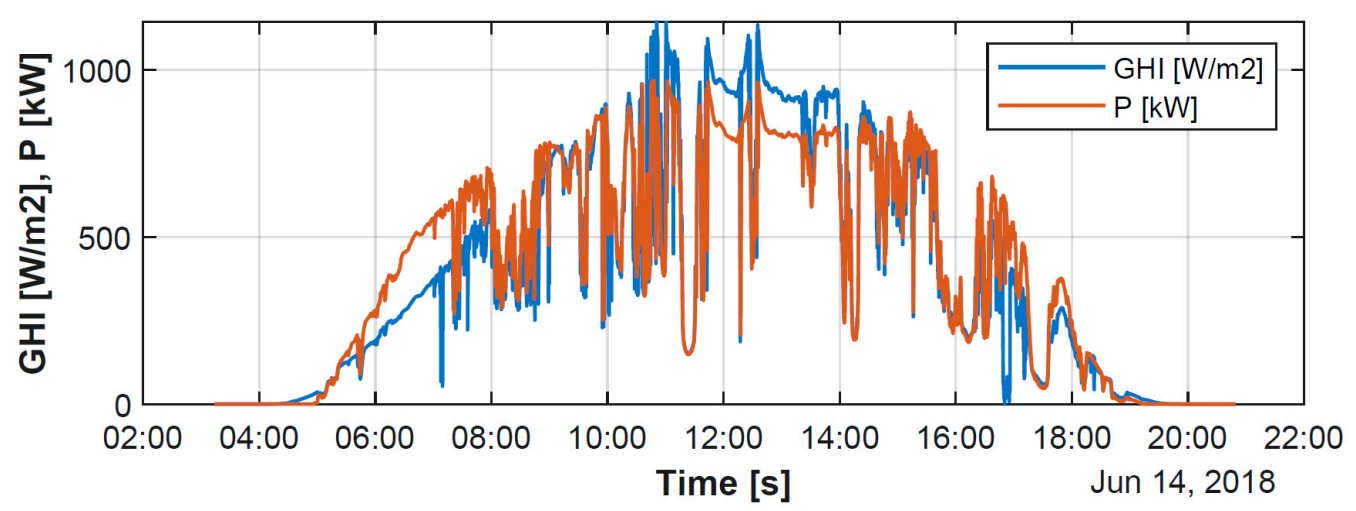

Figure 11. Daily profile of GHI and PV plant power output at the NREL campus in June 2018.

\subsection{Validation Results}

The performance model described in Section 2 is used to simulate the PV plant's active power output using the measured GHI time series. Control method 1 is applied, that is, the PV plant injects all the available power into the grid. In Figure 12, the resulting GHI (a) and active power profile (b) for a time window of $30 \mathrm{~min}$ with significant cloud shadows are shown.

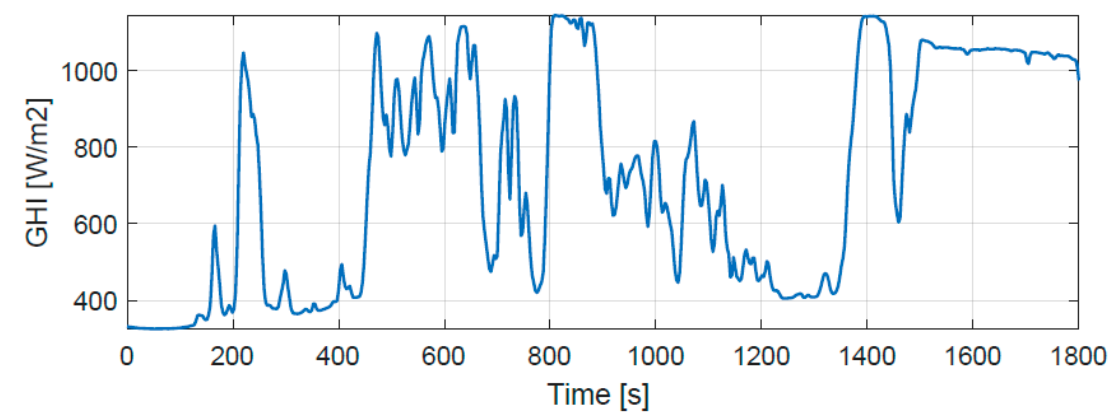

(a)

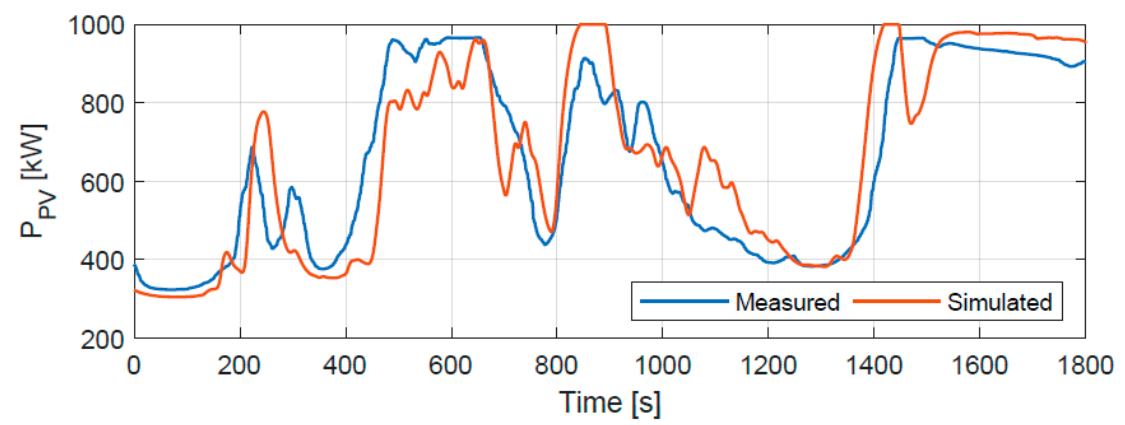

(b)

Figure 12. (a) Solar irradiance profile; (b) power output profile of the PV plant.

One can observe that the simulation model follows the overall trend of the power profile. However, the profile is slightly shifted along the $x$-axis. Leading or lagging time offsets ( $\Delta t= \pm 15$ to $40 \mathrm{~s}$ ) are caused by the location of the meteo station, which observes how GHI declines/rises with certain time delay or time advantage toward the PV plant depending on the direction of cloud movement. Magnitude offsets can be explained by the fact that only GHI data are available and fed into the PV model. A more accurate calculation of the plane-of-array irradiance requires additional measurements of direct normal irradiance (DNI) and diffuse horizontal irradiance (DHI), as validated by studies referenced in the work of [11]. Again, it is noteworthy that the occurring differences between simulations and measurements are mainly caused by the quality of input data, that is, the location and completeness of 
irradiance measurements. However, in order to evidence the model suitability for active power and frequency control studies, it is much more relevant to assess the power generation variability, as stated in Section 3.

By evaluating the smoothing effect of the PV array area, one can notice that large GHI fluctuations (e.g., during $t=[400 \mathrm{~s}, 800 \mathrm{~s}]$ ) are attenuated in the plant power output (both measured and simulated). The cumulative distribution of the rate of change of power is assessed to validate the effectiveness of the first-order time constant, $\tau_{f P V}$, introduced in Section 2. Figure 13 depicts the highest percentiles (95-100\%) of $\frac{\Delta P_{P V}}{\Delta t}$ in p.u./s. A simulation case with $\tau_{f P V}=0$ s exemplifies the high ramp rates that a single PV module would observe (yellow curve). By comparing the simulated and measured ramp rates (red versus blue curve), it is concluded that the performance model provides a satisfactory estimate of the expected power variations of the PV plant with a maximum deviation of $0.5 \%$ up to $99.5 \%$.

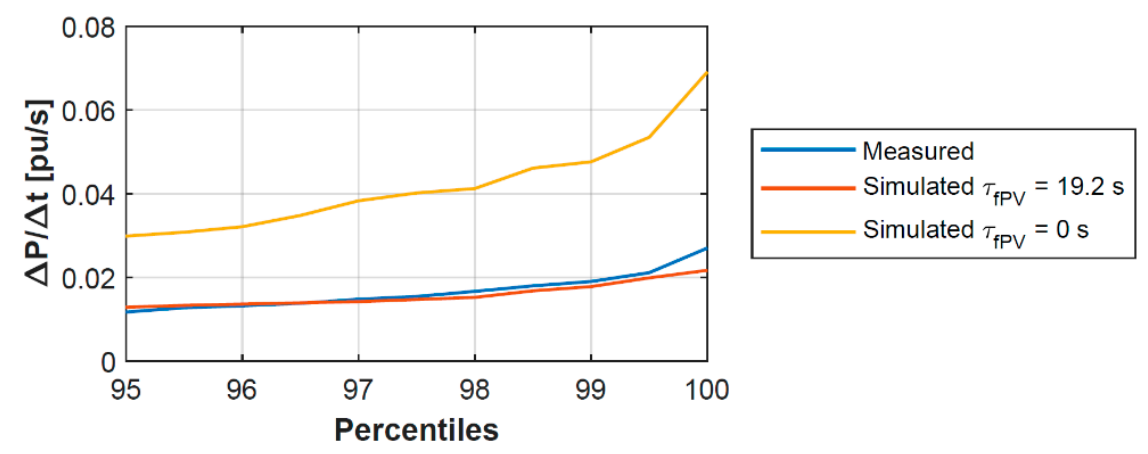

Figure 13. Percentiles of rate of change of power (PV plant).

\section{Battery Energy Storage Model Validation}

\subsection{NREL Battery Energy Storage System-Test Setup}

NREL's 1-MW/1-MWh BESS consisting of LG Li-ion batteries and SMA 2.3-MVA, $400 \mathrm{~V}$ inverter/charger with 1-MVA 13.2-kV/400-V transformer is used for model validation. The BESS test settings are listed in Table 3. The manufacturer guarantees a battery round-trip efficiency of $\varepsilon_{R T}>85 \%$; however, the exact value is unknown.

Table 3. Test data of the battery energy storage system (BESS) under investigation.

\begin{tabular}{cc}
\hline Location & Boulder/USA \\
\hline Type & Lithium-ion polymer \\
\hline Max. continuous power $[\mathrm{kW}]$ & 1000 \\
\hline Installed energy capacity at $100 \% \mathrm{SOH}[\mathrm{kWh}]$ & 1221 \\
\hline Nominal discharge rate & $1-\mathrm{C}$ \\
\hline Guaranteed round-trip efficiency $\varepsilon_{R T}[\%]$ & $>85$ \\
\hline Current SOH [\%] & 99.99 \\
\hline Response time in grid forming mode & 50 ms or faster to return to nominal voltage (within \\
\hline Frequency droop $m_{f}[\% / \mathrm{MW}]$ & $1 \%$ accuracy) \\
\hline Voltage droop $m_{v}[\% / \mathrm{Mvar}]$ & 0.72 \\
\hline Transformer copper losses $[\%]$ & 2.17 \\
\hline Transformer short-circuit voltage $[\%]$ & 0.6 \\
\hline
\end{tabular}


The BESS is operated in grid-forming mode in parallel to NREL's 7-MVA controllable grid interface, which is the virtual point of interconnection to an RSCAD real-time distribution model. The power-hardware-in-the-loop (PHIL) setup is shown in Figure 14 [37].

The first test case assesses the dynamic behavior of the BESS during a load step change. During this test, only circuit breaker CB5 is closed in order to switch on a range of resistive and inductive loads. Circuit breaker CB1 is open during all tests because the system operates in islanded mode.

For the second test case, a realistic two-hour PV power profile is applied at the $924 \mathrm{~kW} \mathrm{PV} \mathrm{system}$ with a constant power factor of $\cos \phi=0.9$. The solar profile is inverted between $t=[30 \mathrm{~min}, 90 \mathrm{~min}]$ to test the BESS in both discharging and charging mode and to capture a wide range of the SOC profile. It enables identifying the exact value of the round-trip efficiency, which battery vendors commonly defined per full charge/discharge cycle. The RL load banks, the 1000-HP motor load, and one capacitor bank are disconnected during the test (CB5, CB3, and SW1 open).

The distribution system (Figure 14) is simulated in MathWorks SimPowerSystems to validate the BESS performance model with grid-forming control, as described in Section 2.

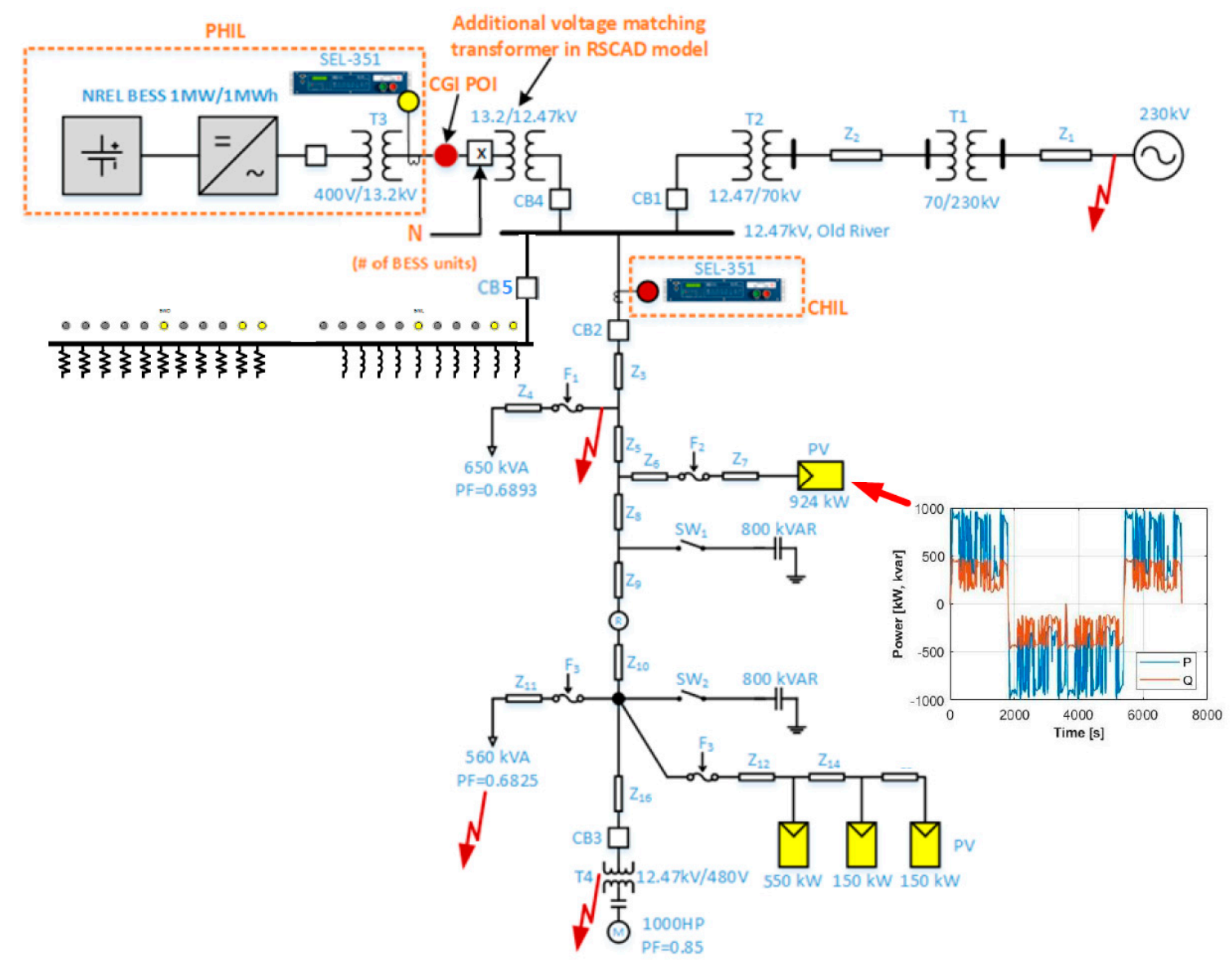

Figure 14. Conceptual diagram of the power-hardware-in-the-loop (PHIL) test setup with NREL's 1-MW/1-MWh battery energy storage system (BESS).

\subsection{Validation Results}

\subsubsection{Grid-Forming Control—Load Step Change}

In Figure 15, the transient responses of frequency (a), voltage (b), active power (c), and reactive power (d) after switching on a $500 \mathrm{~kW} / 500 \mathrm{kVAr}$ load at $t=5 \mathrm{~s}$ are depicted. Measurements are taken on the HV side of the BESS transformer, that is, the BESS PoC. The frequency is estimated by a phase locked loop (PLL) with a lowpass filter cut-off frequency of $10 \mathrm{~Hz}$. Voltage and power 
signals are processed with a lowpass filter cut-off frequency of $10 \mathrm{~Hz}$. The results show that the BESS performance model is capable of emulating the transient response after a load step change to a large extent. Deviations in frequency undershoot are related to PLL dynamics. However, they do not affect the actual transient response of frequency according to active power ( $\mathrm{f} / \mathrm{P}$ droop). The simulation model captures the voltage dynamics with regard to settling time. Small deviations in rise time and undershoot are visible. The transient responses of active and reactive power are estimated precisely with only small deviations in overshoot. Any deviations can be explained by a lack of knowledge on the exact inverter control structure, which is proprietary information of the manufacturer. It should be noted that the transient response of the inverter is tightly coupled with the internal control loops, ramp limiters and present communication delays.

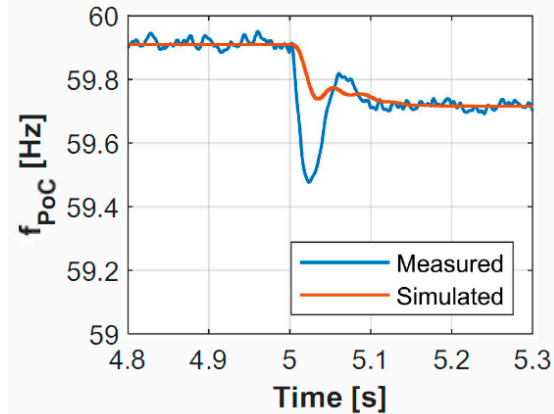

(a)

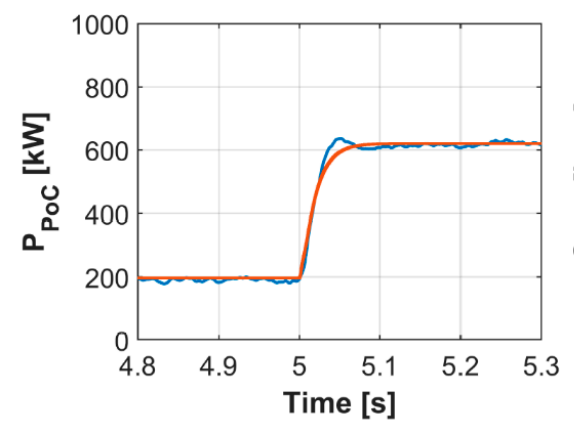

(c)

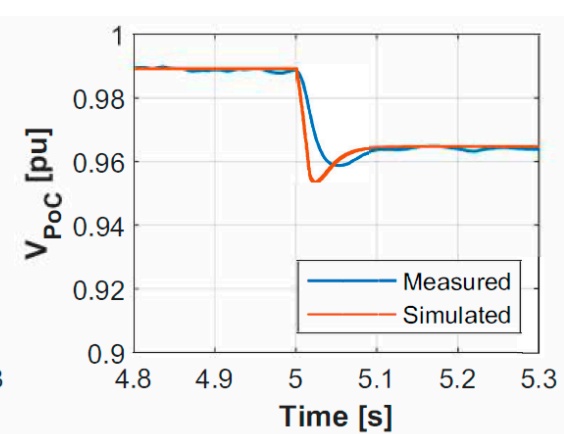

(b)

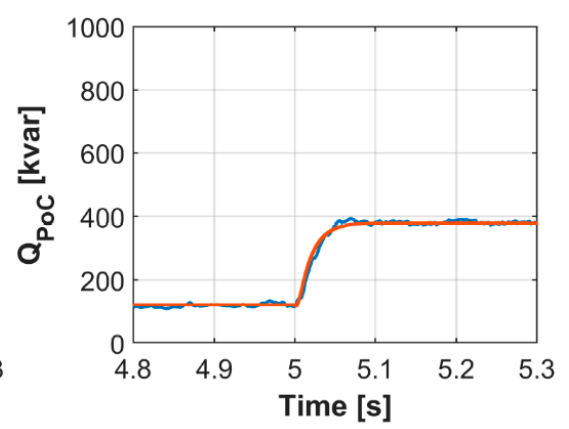

(d)

Figure 15. BESS load step response test. (a) Frequency; (b) voltage; (c) active power; (d) reactive power.

\subsubsection{Grid-Forming Control-PV Profile}

Figures 16 and 17 show the measured and simulated two-hour profiles of $\mathrm{f}, \mathrm{P}, \mathrm{V}$, and $\mathrm{Q}$ at the BESS PoC. Figure 18 plots the frequency versus active power (a) and voltage versus reactive power (b). Notice that frequency and voltage adjustments according to active and reactive power variations, respectively, are predicted with good accuracy by considering the inverter droop gain, $m_{v}$, and the transformer V/Q droop. Some outliers are observed for voltage/reactive power in Figure 18, which are caused by some numerical simulation errors being visible in the voltage for $t<1000 \mathrm{~s}$ (Figure 17a). The simulation deviations are less than $1 \%$ of nominal voltage and frequency, respectively, and less than $5 \%$ of the rated power.

\subsubsection{State-of-Charge Estimation}

The active power of the BESS measured at the MV interconnection is provided as input to the model described in Section 2. The insignificant transformer copper losses (see Table 3) are neglected during the SOC calculation. It is assumed that the total energy capacity is available because the $\mathrm{SOH}$ is close to $100 \%$ (see Table 3). The initial SOC value is $S O C_{i n i}=52.5 \%$. Figure 19a shows the SOC profile provided by the BMS and simulation model during the two-hour test. 


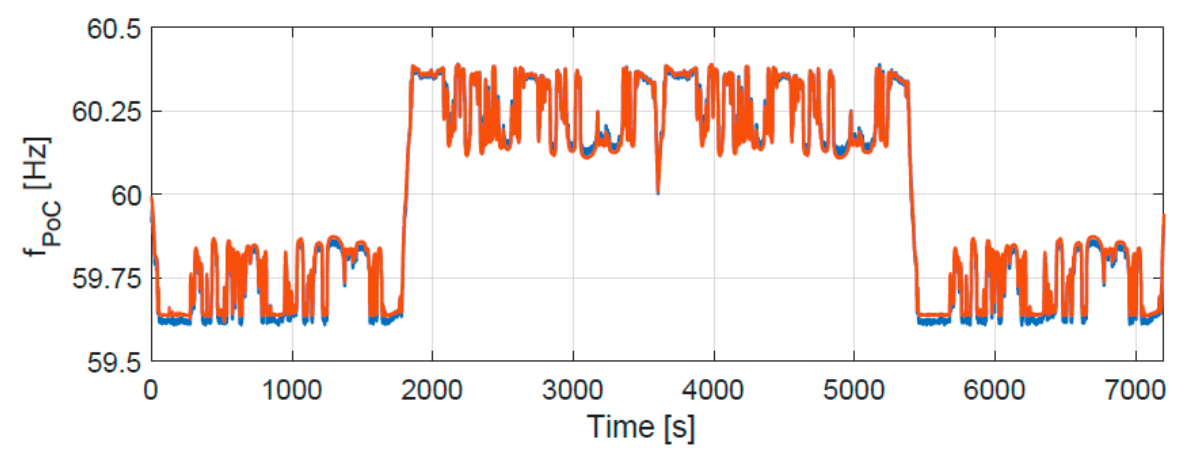

(a)

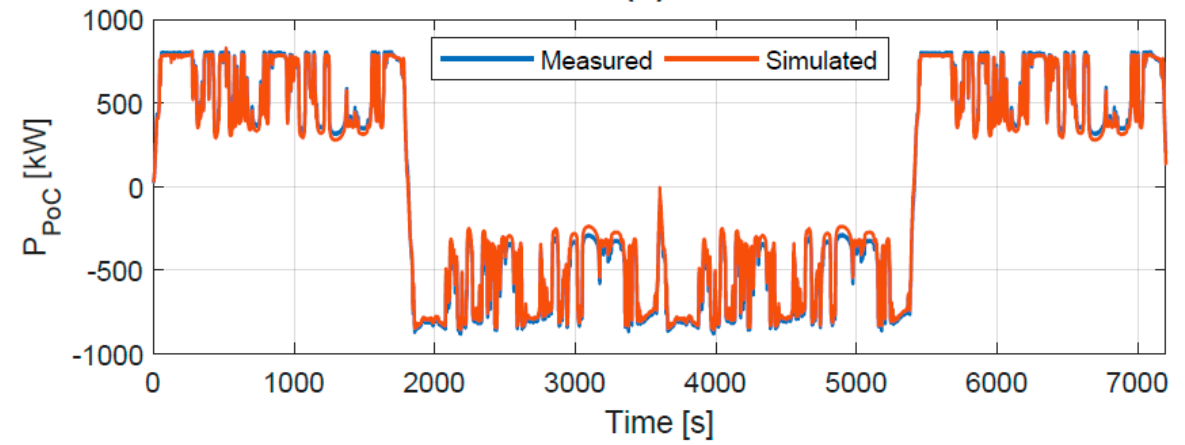

(b)

Figure 16. BESS two-hour profile. (a) Frequency; (b) active power.

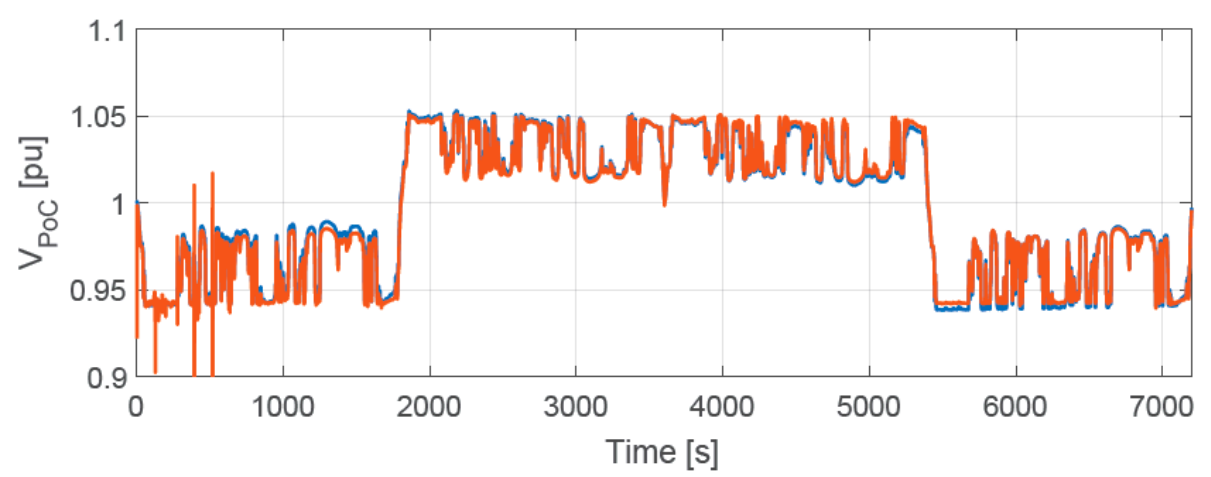

(a)

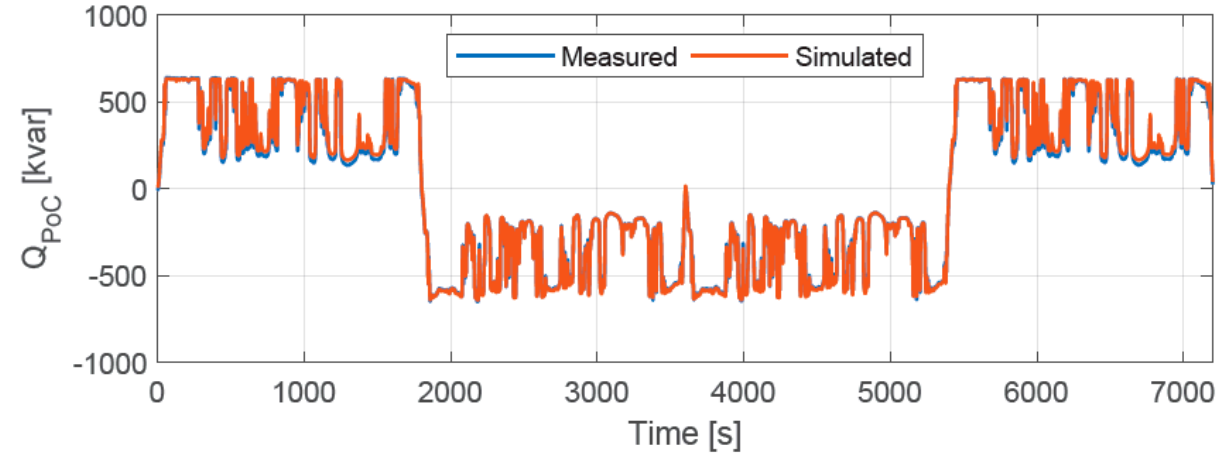

(b)

Figure 17. BESS two-hour profile. (a) Voltage; (b) reactive power. 


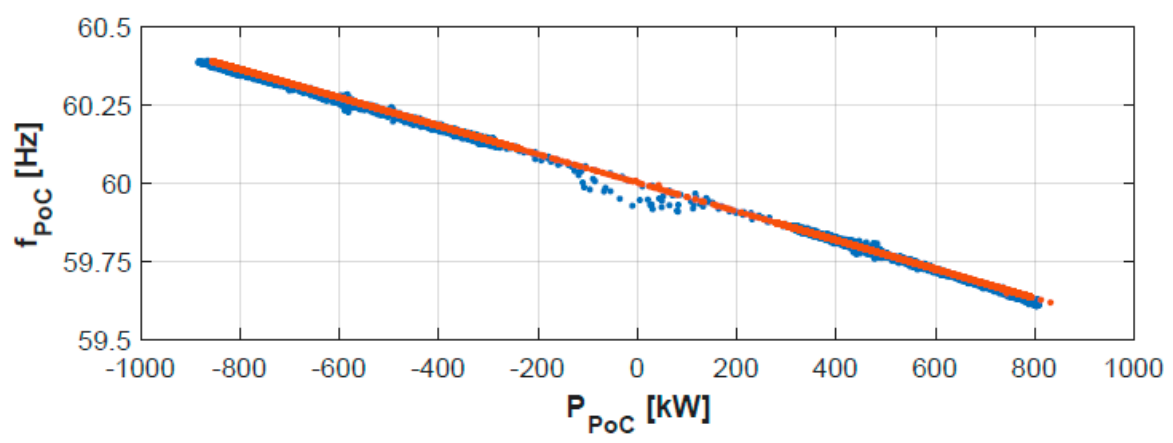

(a)

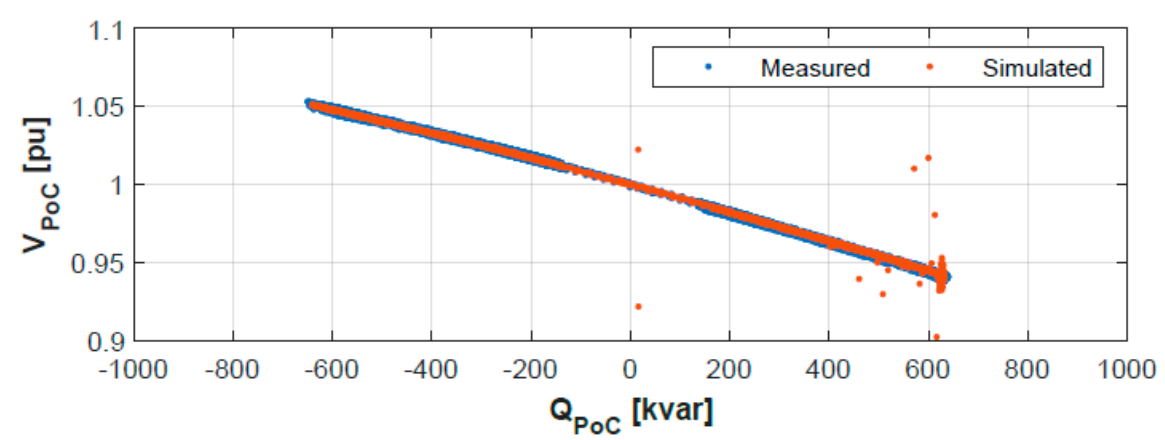

(b)

Figure 18. (a) BESS f/P droop at PoC; (b) BESS V/Q droop at PoC.

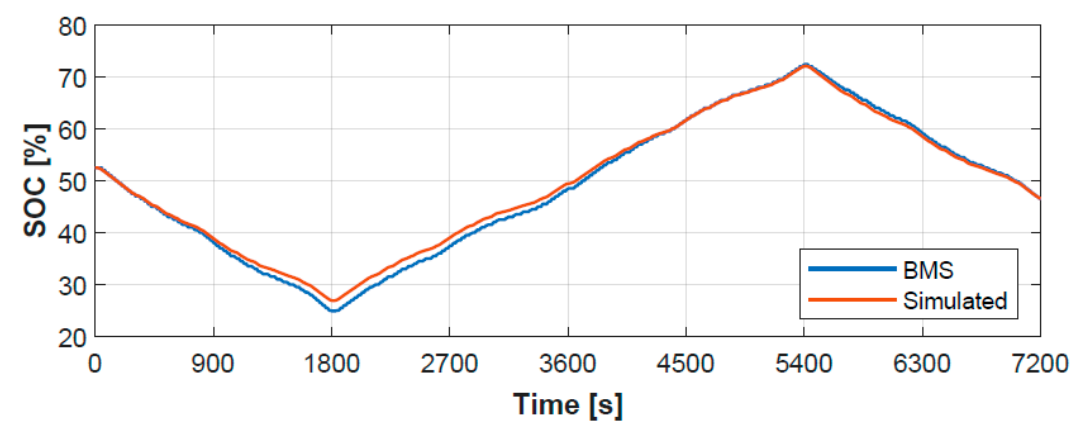

(a)

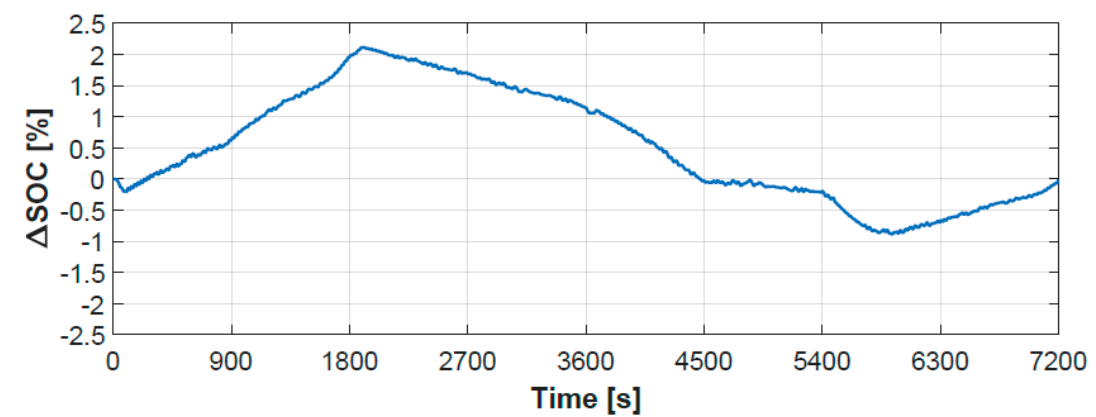

(b)

Figure 19. (a) BESS state-of-charge (SOC) profile (b) deviation between simulation and measurement.

The round-trip efficiency is calculated to be $\varepsilon_{R T}=89 \%$ based on the supposition that the BMS and simulated SOC at $t=0 \mathrm{~s}$ and $t=7200 \mathrm{~s}$ shall be equal after one cycle with a depth of $47.5 \%$. By comparing both SOC estimations by the BMS and developed model, one can observe that the Wh-counting method provides accurate results with deviations of less than $2 \%$ (Figure 19b). The maximum deviation of 
$\triangle S O C=2.1 \%$ is accumulated during the discharge periods. It is noteworthy that the SOC decreases during $t=[5400 \mathrm{~s}, 7200 \mathrm{~s}]$, although the BESS delivers the same energy to the grid (see Figure 16). This implies that the discharging efficiency depends on the actual SOC level, as ascertained in the work of [18]. Overall, the results demonstrate that the Wh-counting method yields satisfactory SOC estimation during a realistic discharge/charge cycle of the BESS with a volatile power profile fluctuating between zero and rated power. Moreover, the model can be used to calculate the actual real-time efficiency in regular intervals because it might change depending on the battery $\mathrm{SOH}$.

Note that the nominal discharge rate (1C) is not exceeded during the test. Higher C-rates might alter the discharge process and hence lead to larger SOC estimation errors [18]. The Wh-counting method for SOC prediction cannot remain accurate for a long time because of sensor accuracy of current/power measurements, as well as temperature, self discharge rate, and capacity fading affecting the battery performance. Hence, it is important to regularly update the initial SOC value (e.g., daily, weekly) and the $\mathrm{SOH}$ value (e.g., monthly) based on the BMS information.

\section{Conclusions and Outlook}

In this paper, performance models of a WTG, PV plant, and BESS were proposed and validated through field measurements. The relevant background related to the necessity of such performance models was emphasized and the benefits compared to state-of-the-art models were highlighted. Extensive power system simulation studies with high numbers of various DERs (e.g., multi-MW hybrid power plants, low-voltage feeders with high PV penetration, microgrids) require reduced-order DER performance models to reduce the computational effort of such simulations. Because of their computational performance, such models can be used in combination with economic dispatch and production cost models to validate the impact of reliability constraints on system costs. Further, the described performance models will accelerate and reduce the complexity of various model-based design stages (control development, RT-HIL testing) in power systems, for example, for HPPC functions.

Section 2 outlined the scope, interface with other models, as well as the application purposes of the DER performance models. They are applicable for power system stability studies involving active and reactive power, as well as frequency and voltage control. Subsequently, a detailed description of each model (WTG, PV, BESS) was provided. All performance models were described as a PQ controlled system. Additionally, a grid-forming model of the BESS was presented as a Vf controlled system.

Section 3 addressed the scope and performance metrics of the validation work of this paper. One of the most essential aspects is the correct estimation of power generation variability according to fluctuations in wind speed and solar irradiance because it determines, for example, the BESS control requirements in HPPs, for example, for power gradient reduction, frequency control, or capacity firming. Wind speed and active power measurements of two Vestas WTGs of various ratings $(850 \mathrm{~kW}$ and $2 \mathrm{MW}$ ) were used for model validation, as presented in Section 4. The PV model was assessed using solar irradiance and active power measurements of a 1-MW PV plant (Section 5). Both the WTG and PV performance models predicted one second variations of active power output with good precision. Time and magnitude offsets between measurement and simulation can be associated with the quality of resource data, that is, wind speed and solar irradiance. However, these deviations do not harm the applicability of the models, as they are primarily designed to assess dynamic phenomena related to active and reactive power as well as frequency and voltage control.

The validation of the BESS performance model was divided into assessments of (1) grid-forming control and (2) SOC estimation (Section 6). A PHIL setup with a 1-MW/1-MWh BESS under test was used to generate data during a two-hour time period with a volatile load profile. The validation process showed that frequency and voltage adjustments according to active and reactive power variations, respectively, were predicted with good accuracy. Then, the BESS performance model enabled us to determine the exact value of the round-trip efficiency. The resulting SOC profile was predicted with a maximum deviation of $\triangle S O C=2.1 \%$, which is satisfactory considering the safety margins for the usable SOC range that are usually applied in grid applications. 
The validation work presented in this paper proves that the proposed performance models for DERs are suitable for power system integration studies and hybrid power plant control design in all model-based design stages, that is, preliminary analysis, design, verification, and validation in a RT-HIL framework with a high level of confidence. These simple, yet accurate models capture the overall response of the considered assets, that is, WTG, PV, and BESS, with deviations of less than $5 \%$. Validation of remaining model features, that is, $\mathrm{P}$ and $\mathrm{Q}$ reference tracking of grid-following DERs, is not essential for the validity of the proposed performance models. A follow-up paper focusing on these model elements is in progress anyhow.

Author Contributions: Conceptualization, L.P. and F.I.; Methodology, L.P. and F.I.; Validation, L.P.; Formal Analysis, L.P.; Investigation, L.P.; Resources, G.C.T., V.G., P.K., and D.-I.S.; Writing-original draft, L.P.; Writing-review and editing, L.P.; Supervision, F.I. and G.C.T.

Funding: This work was carried out as part of the Ph.D. project "Proof-of-Concept on Next Generation Hybrid Power Plant Control". Innovation Fund Denmark is acknowledged for financial support through the Industrial $\mathrm{PhD}$ funding scheme. Additional funding by the Danish ForskEL-program through RemoteGRID project and by the European Union's Horizon 2020 research and innovation programme through Net2DG project (grant agreement no 774145) is acknowledged. This work was authored [in part] by the National Renewable Energy Laboratory, operated by Alliance for Sustainable Energy, LLC, for the U.S. Department of Energy (DOE) under Contract No. DE-AC36-08GO28308. The views expressed in the article do not necessarily represent the views of the DOE or the U.S. Government. The U.S. Government retains and the publisher, by accepting the article for publication, acknowledges that the U.S. Government retains a nonexclusive, paid-up, irrevocable, worldwide license to publish or reproduce the published form of this work, or allow others to do so, for U.S. Government purposes.

Acknowledgments: Special acknowledge to the National Renewable Energy Laboratory, Golden/USA and the wind energy department of Danish Technical University, Risø/Denmark for the provision of field measurement data.

Conflicts of Interest: The authors declare no conflict of interest.

\section{References}

1. Petersen, L.; Borsotti-Andruszkiewicz, R.M.; Tarnowski, G.C.; Hesselbæk, B.; Martinez, A.; Steggel, N.; Osmond, D. Vestas Power Plant Solutions Integrating Wind, Solar PV and Energy Storage. In Proceedings of the 3rd International Hybrid Power Systems Workshop, Tenerife, Spain, 8-9 May 2018.

2. Dykes, K.; King, J.; Diorio, N. Research Opportunities in the Physical Design Optimization of Hybrid Power Plants. In Proceedings of the 4th International Hybrid Power Systems Workshop, Crete, Greece, 22-23 May 2019.

3. Klonari, V.; Fraile, D.; Rossi, R.; Schmela, M. Exploring the Viability of Hybrid Wind-Solar Power Plants. In Proceedings of the 4th International Hybrid Power Systems Workshop, Crete, Greece, 22-23 May 2019.

4. $\quad$ Das, K.; Hansen, A.D.; Koivisto, M.; Sørensen, P.E. Enhanced Features of Wind-Based Hybrid Power Plants. In Proceedings of the 4th International Hybrid Power Systems Workshop, Crete, Greece, 22-23 May 2019.

5. Elkadragy, M.M.; Baumann, M.; Moore, N.; Weil, M.; Lemmertz, N. Contrastive Techno-Economic Analysis Concept for Off-Grid Hybrid Renewable Electricity Systems Based on comparative case studies within Canada and Uganda. In Proceedings of the 3rd International Hybrid Power Systems Workshop, Tenerife, Spain, 8-9 May 2018.

6. Petersen, L.; Iov, F.; Tarnowski, G.C.; Carrejo, C. Optimal and Modular Configuration of Wind Integrated Hybrid Power Plants for Off-Grid Systems. In Proceedings of the 3rd International Hybrid Power Systems Workshop, Tenerife, Spain, 8-9 May 2018.

7. Bitaraf, H.; Buchholz, B. Reducing energy costs and environmental impacts of off-grid mines. In Proceedings of the 3rd International Hybrid Power Systems Workshop, Tenerife, Spain, 8-9 May 2018.

8. Raducu, A.G.; Styliaras, N.; Funkquist, J.; Ionita, C.; Ab, V. Design and Implementation of a Hybrid Power Plant Controller. In Proceedings of the 3rd International Hybrid Power Systems Workshop, Tenerife, Spain, 8-9 May 2018.

9. Petersen, L.; Iov, F.; Tarnowski, G.C.; Raghuchandra, K.B. Methodological Framework for Stability Analysis, Control Design and Verification in Hybrid Power Plants. In Proceedings of the 4th International Hybrid Power Systems Workshop, Crete, Greece, 22-23 May 2019. 
10. Hansen, A.D.; Margaris, I.D.; Tarnowski, G.C.; Iov, F. Simplified Type 4 wind turbine modeling for future ancillary services. In Proceedings of the European Wind Energy Conference \& Exhibition, Vienna, Austria, 4-7 February 2013.

11. Kratochvil, J.A.; Boyson, W.E.; King, D.L. Photovoltaic Array Performance Model; Technical Report; Sandia National Laboratories: Albuquerque, NM, USA, 2004.

12. Kawabe, K.; Tanaka, K. Impact of Dynamic Behavior of Photovoltaic Power Generation Systems on Short-Term Voltage Stability. IEEE Trans. Power Syst. 2015, 30, 3416-3424. [CrossRef]

13. Chinuki, T.; Taniguchi, H.; Nakajima, T.; Ota, Y.; Suzuki, H. System Reduction of Power System with Penetration of Photovoltaic Generations. Electr. Eng. Japan 2014, 188, 31-43. [CrossRef]

14. Marcos, J.; Marroyo, L.; Lorenzo, E.; Alvira, D.; Izco, E. Power output fluctuations in large scale pv plants: One year observations with one second resolution and a derived analytic model. Prog. Photovolt. Res. Appl. 2011, 19, 218-227. [CrossRef]

15. Marcos, J.; Marroyo, L.; Lorenzo, E.; Alvira, D.; Izco, E. From irradiance to output power fluctuations: The pv plant plant as a low pass filte. Prog. Photovolt. Res. Appl. 2011, 19, 505-510. [CrossRef]

16. Gao, D.W. Energy Storage for Sustainable Microgrid, 1st ed.; Elsevier: Amsterdam, the Netherlands, 2015; ISBN 9780128033746.

17. Zhang, R.; Xia, B.; Li, B.; Cao, L.; Lai, Y.; Zheng, W.; Wang, H.; Wang, W. State of the art of lithium-ion battery SOC estimation for electrical vehicles. Energies 2018, 11, 1820. [CrossRef]

18. Soon Ng, K.; Moo, C.-S.; Chen, Y.-P.; Hsieh, Y.-C. Enhanced coulomb counting method for estimating state-of-charge and state-of-health of lithium-ion batteries. Elsevier Appl. Energy 2019, 8, 55.

19. Petersen, L.; Iov, F.; Hansen, A.D.; Altin, M. Voltage Control Support and Coordination between Renewable Generation Plants in MV Distribution Systems. In Proceedings of the 15th Wind Integration Workshop, Vienna, Austria, 15-17 November 2016.

20. Ionita, C. Advanced Active Power and Frequency Control of Wind Power Plants. Master's Thesis, Aalborg University, Aalborg, Denmark, 2017. Available online: https://vbn.aau.dk (accessed on 11 October 2019).

21. Pombo, D.V. Coordinated Frequency and Active Power Control of Hybrid Power Plants. Master's Thesis, Aalborg University, Aalborg, Denmark, 2018. Available online: https://vbn.aau.dk (accessed on 11 October 2019).

22. Pombo, D.V.; Iov, F.; Stroe, D.-I. A Novel Control Architecture for Hybrid Power Plants to Provide Coordinated Frequency Reserves. Energies 2019, 12, 919. [CrossRef]

23. IEC 61400-27-1 Ed.1.0-Wind Turbines-Part 27-1: Electrical Simulation Models—Wind Turbines; International Standard; ANSI: Washington, DC, USA, 2015.

24. Iov, F.; Shahid, K.; Petersen, L.; Olsen, L.R. RePlan Project: D5.1-Verification of Ancillary Services in Large Scale Power System; Project Report; Replan Project: Aalborg, Denmark, 2018; Available online: www.replanproject.dk (accessed on 11 October 2019).

25. Petersen, L.; Iov, F.; Shahid, K.; Olsen, R.L.; Altin, M.; Hansen, A.D. RePlan Project: D2—Voltage Control Support and Coordination between ReGen Plants in Distribution Systems; Project Report; Replan Project: Aalborg, Denmark, 2016; Available online: www.replanproject.dk (accessed on 11 October 2019).

26. Tang, C.; Pathmanathan, M.; Soong, W.L.; Ertugrul, N. Effects of inertia on dynamic performance of wind turbines. In Proceedings of the Australasian Universities Power Engineering Conference, Sydney, Australia, 14-17 December 2008.

27. Vestas Wind Systems Technology General Specification, V112-3.0 MW 50/60 Hz, Class 1; Public Report; DRE: Aarhus, Denmark, 2011.

28. Petersen, L.; Kryezi, F. Wind Power Plant Control Optimisation with Embedded Application of Wind Turbines and STATCOMs. Master's Thesis, Aalborg University, Aalborg, Denmark, 2015. Available online: vbn.aau.dk (accessed on 11 October 2019).

29. Rocabert, J.; Luna, A.; Blaabjerg, F. Control of Power Converters in AC Microgrids. IEEE Trans. Power Electron. 2012, 27, 4734-4749. [CrossRef]

30. Stroe, D.-I. Lifetime Models for Lithium Ion Batteries used in Virtual Power Plants. Ph.D. Thesis, Aalborg University, Aalborg, Denmark, 2014. Available online: vbn.aau.dk (accessed on 11 October 2019).

31. Knap, V.; Chaudhary, S.K.; Stroe, D.-I.; Swierczynski, M.J.; Craciun, B.-I.; Teodorescu, R. Sizing of an Energy Storage System for Grid Inertial Response and Primary Frequency Reserve. IEEE Trans. Power Syst. 2016, 31, 3447-3456. [CrossRef] 
32. Swierczynski, M.; Stroe, D.I.; Stan, A.I.; Teodorescu, R. Primary Frequency Regulation with Li-ion Battery Energy Storage System: a Case Study for Denmark. In Proceedings of the ECCE Asia, Melbourne, Australia, 3-6 June 2013.

33. Barahona, B.; Cutululis, N.A.; Trombe, P.J.; Pinson, P. Regime-based supervisory control to reduce power fluctuations from offshore wind power plants. In Proceedings of the IEEE PowerTech Conference, Grenoble, France, 16-20 June 2013; pp. 1-6.

34. Ciontea, C.-I.; Sera, D.; Iov, F. Influence of Resolution of the Input Data on Distributed Generation Integration Studies. In Proceedings of the International Conference on Optimization of Electrical and Electronic Equipment (OPTIM), Brasov, Romania, 22-24 May 2014.

35. Tarnowski, G.C. Coordinated Frequency Control of Wind Turbines in Power Systems with High Wind Power Penetration. Ph.D. Thesis, Technical University of Denmark, Lyngby, Denmark, 2010. Available online: https://orbit.dtu.dk/en/ (accessed on 11 October 2019).

36. Wagner, R.; Cañadillas, B.; Clifton, A.; Feeney, S.; Nygaard, N.; Poodt, M.; Martin, C.S.; Tüxen, E.; Wagenaar, J.W. Rotor equivalent wind speed for power curve measurement-comparative exercise for IEA Wind Annex 32. In Proceedings of the 5th International Conference on The Science of Making Torque from Wind 2014, Lyngby, Denmark, 10-20 June 2014.

37. Kuga, R.; Esguerra, M.; Chabot, B.; Avendano Cecena, A. EPIC 2.05: Inertia Response Emulation for DG Impact Improvement; EPIC_Final Report; Pacific Gas and Electric Company: San Francisco, CA, USA, 2019.

(C) 2019 by the authors. Licensee MDPI, Basel, Switzerland. This article is an open access article distributed under the terms and conditions of the Creative Commons Attribution (CC BY) license (http://creativecommons.org/licenses/by/4.0/). 